\title{
Vibration Analysis and Models of Adjacent Structures Controlled by Magnetorheological Dampers
}

\author{
Michela Basili and Maurizio De Angelis \\ Department of Structural and Geotechnical Engineering, Sapienza University of Rome, Via Eudossiana 18, Rome, Italy \\ Correspondence should be addressed to Michela Basili; michela.basili@uniromal.it
}

Received 5 August 2016; Revised 22 December 2016; Accepted 18 January 2017; Published 28 March 2017

Academic Editor: Athanasios Chasalevris

Copyright (C) 2017 Michela Basili and Maurizio De Angelis. This is an open access article distributed under the Creative Commons Attribution License, which permits unrestricted use, distribution, and reproduction in any medium, provided the original work is properly cited.

\begin{abstract}
This paper deals with the vibration analysis of adjacent structures controlled by a magnetorheological (MR) damper and with the discussion of a numerical procedure for identification and definition of a reliable finite element model. The paper describes an extensive experimental campaign investigating the dynamic response, through shaking table tests, of a tridimensional four-story structure and a two-story structure connected by an MR device. Several base excitations and intensity levels are considered. The structures were tested in nonconnected and connected configuration, with the MR damper operating in passive or semiactive mode. Moreover, the paper illustrates a procedure for the structural identification and the definition of a reliable numerical model valid for adjacent structures connected by MR dampers. The procedure is applied in the original nonconnected configuration, which represents a linear system, and then in the connected configuration, which represents a nonlinear system due to the MR damper. In the end, the updated finite element model is reliable and suitable for all the considered configurations and the mass, damping, and stiffness matrices are derived. The experimental and numerical responses are compared and the results confirm the effectiveness of the identification procedure and the validation of the finite element model.
\end{abstract}

\section{Introduction}

Different control techniques are available for structural protection against dynamic actions [1]. Control devices are conveniently positioned in the structures to limit the dynamic response. In the context of civil engineering, control techniques may be applied to different structural configurations, such as buildings and bridges. Bridges' and single buildings' cases are usually analyzed and examined in depth, whereas the case of adjacent buildings and more generally of adjacent structures is less studied; however, this case seems just as interesting and peculiar, since the closeness of the structures can be conveniently used to link them through special control devices. Such a solution may be applied to reduce one or both structural responses, according to the control strategy selected, and may also overcome the problem of pounding, if necessary. For different reasons, civil structures are often built close to each other, but such a situation is also frequently observed in other engineering branches. In fact, it is not rare to find different components located in the same industrial plant within a small space, or various machineries adjacently positioned in mechanical factories, or contiguous elements in aerospace applications and so on.

Some theoretical studies exist in which structural control is effectively applied to adjacent structures by means of passive viscoelastic [2,3] or hysteretic [4-7] devices, or using semiactive or active devices [8-10]. Concerning the use of semiactive devices, $[8,10]$ deals with aspects related to the design of an appropriate control law comparing through numerical models different control strategies, while in [9] the effectiveness of MR damper is examined for seismic response mitigation under coupled building control scheme, involving passive and semiactive control strategies. Moreover, the influence of damper location and maximum command voltage on control performance is also examined.

Concerning the experimental studies, most of them focus on passive devices [11-14], while only few deal with active and semiactive control [15-18] and the experiments are usually performed utilizing a reduced number of dynamic inputs. References $[15,16,18]$ present experiments that make use of 
semiactive control strategy, whereas [17] reports an experimentation performed using active control. In particular, $\mathrm{Xu}$ et al. [18] presented an experimental investigation to explore the possibility of using magnetorheological dampers to connect a podium structure to a multistory building. The dynamic characteristics of the two buildings without any connection and with a rigid connection were first identified. Then two building models without any connection with the rigid connection and with the MR damper were tested under the El Centro seismic ground motion. To the author's knowledge, an extensive dynamic experimentation on adjacent structures connected with magnetorheological (MR) dampers is illustrated only in [15].

Another crucial role, when dealing with these features, is played by the identification of these types of structures. In fact, when the mechanical characteristics are known, it is possible to determine if damage occurred in the structure, especially after significant events. In literature, there are examples of identification on controlled structures [17-23]. For the most part, studies concern the identification of the modal parameters (frequencies, damping factors, and mode shapes) of the structures with or without control devices and the identification of frequency response functions (FRFs), for example, [17, 18]. At most, a state-space model is defined, while a complete finite element model and the representation with the second-order formulation are not often supplied. Notwithstanding, the knowledge of a complete numerical model, when fine-tuned to the experimental response through a calibration of mechanical properties, is an important instrument that can even be used to make predictions on the future structural response.

In this respect, the present paper deals with the vibration analysis of adjacent structures controlled by a magnetorheological (MR) damper and with the discussion of a numerical procedure for the identification and definition of a reliable finite element model (FEM). The tridimensional physical model consists of a four-story structure and a two-story structure connected at the second level by the control device, with the possibility of acting in passive or in semiactive mode. Another paper by the authors in [15] analyzed the theoretical aspects of the control strategy applied to adjacent structures and evaluated the effectiveness to reduce structural responses. The main contribution of the paper is the description of an extensive experimental campaign with shaking table tests devoted to investigating the dynamic behavior of the uncoupled and coupled structures; then, it also makes use of experimental results to illustrate a procedure aiming to achieve the structural identification and the definition of a reliable numerical model for adjacent structures connected by control devices. Since the approach presented is general, it is usable also for different kinds of control devices. The campaign is carried out on a shaking table using a wide variety of base excitations such as sine sweep, white noise, and natural earthquakes, at several intensities. The method for the identification procedure and model definition follows three steps: (i) the vibration analysis of the system, (ii) the identification of first-order modal models from experimental data through the ERA/OKID algorithm $[24,25]$, and (iii) the definition of an accurate finite element model by means of an

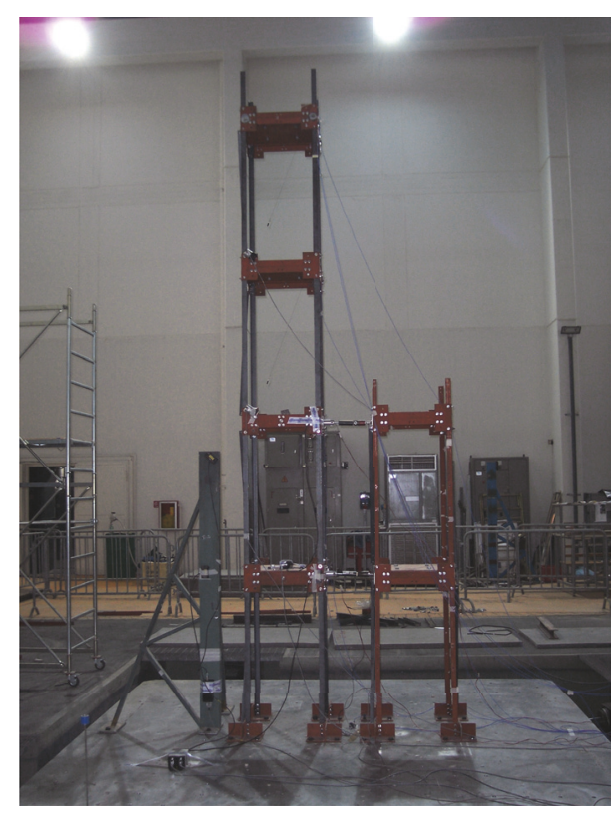

FIgURE 1: Tridimensional physical model mounted on the shaking table with MR damper at the second story.

updating procedure. The procedure is applied at a first stage in the original nonconnected configuration, which represents a linear system, and then in the connected configuration, which represents a nonlinear system due to the presence of the MR damper.

In the end, an updated finite element model, reliable and suitable for all the examined configurations, is obtained and the mass, damping, and stiffness matrices for a second-order formulation are supplied.

The paper is organized as follows. Section 2 describes the test set-up and experimental program; Section 3 defines the identification procedure and model definition; Section 4 presents the results carried out on the nonconnected configuration, whereas Section 5 presents analogous results for the connected configuration. Finally, Section 6 concludes with a summary about the dynamics, identification, and finite element modeling of adjacent structures controlled by MR dampers.

\section{Description of the Test Set-Up and Experimental Program}

2.1. Physical Model and MR Damper. The tridimensional physical model consists of a pair of structures (a 4-story and a 2-story one) of different heights, Figure 1. It is a laboratory 1:5 scaled model (length scale $\lambda_{L}=5$ ). The taller structure is $4.80 \mathrm{~m}$ high and has a total mass of $520 \mathrm{Kg}$ (structure A). The shorter structure is $2.40 \mathrm{~m}$ high and has a total mass of $256 \mathrm{Kg}$ (structure B). Both of them have plan dimensions of $0.60 \times 0.60 \mathrm{~m}$ and an interstory height of $1.20 \mathrm{~m}$, with main dimensions shown in Figures 2(a) and 2(b); the distance between the structures is $0.40 \mathrm{~m}$. Frames are made of steel Fe360, using common profiles L40 $\times 40 \times 4 \mathrm{~mm}$; all the connections are bolted. Four steel plates, with total mass of 


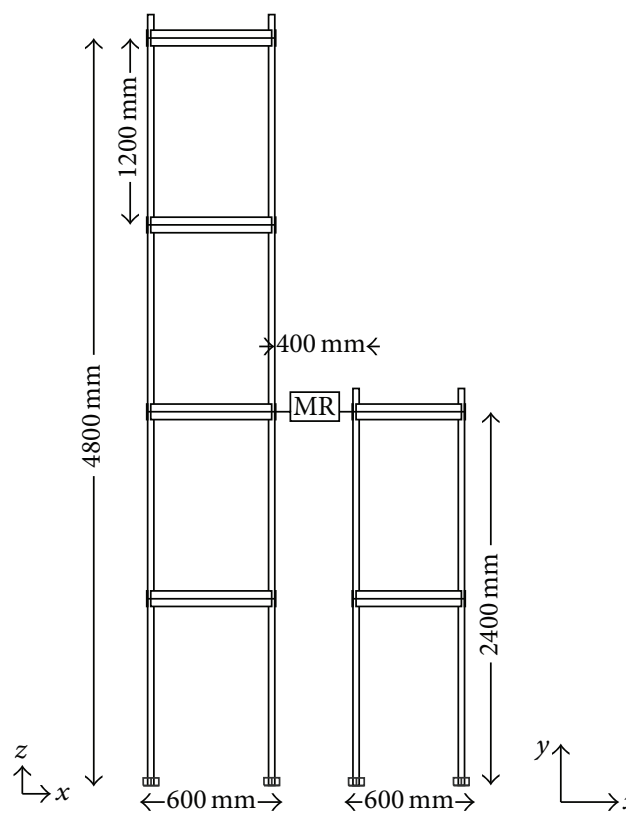

(a)
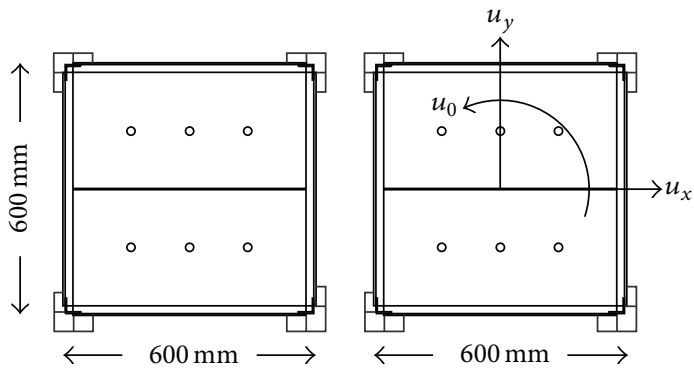

(b)

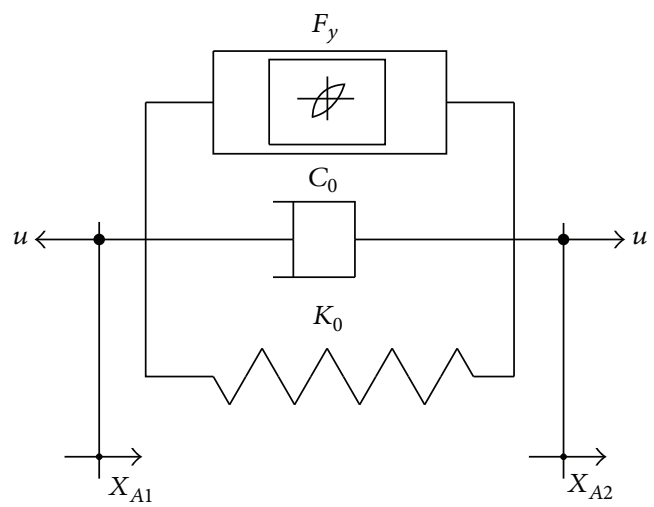

(c)

FIGURE 2: Dimensions of the adjacent structures and MR damper numerical model: (a) elevations; (b) plan, with model's degrees of freedom; (c) device numerical model.

$80 \mathrm{~kg}$, are placed at each level. Both structures are braced in the $y z$ direction in order to provide a substantially planar dynamic behavior. However, the number and placement of these bracings, Figure 3, provides a weak modal coupling (translation in $x$ direction and rotation): the physical model is not perfectly symmetric with respect to $x$ direction; for this reason the problem is not perfectly plane.

An MR damper is installed at the second level between the structures. The device uses the typical property of controllable magnetorheological fluids: when exposed to a magnetic field, it can change in milliseconds its characteristics from a linear viscous fluid to a semisolid state. The literature reports many applications of MR dampers in several engineering fields, including mechanics, aerospace and robotic [26], and also biomedical [27] and civil engineering [28]. The prototype of the MR damper is the RD-1005-3 model, produced by the Lord Corporation. The maximum current supplied is $1 \mathrm{~A}$ DC, which corresponds to an input voltage of $2.5 \mathrm{~V}$, whereas the minimum corresponds to $0 \mathrm{~V}$. The damper has a maximum stroke of $\pm 25 \mathrm{~mm}$, and the maximum extension force should be kept below $4448 \mathrm{~N}$. As the magnetic field is applied, the damping characteristics of the fluid increase with a response time of about 25 milliseconds. It can operate in passive (constant voltage) and semiactive (variable voltage in accordance with a specific control strategy) mode.

2.2. Shaking Table and Measurement Instruments. Shaking table tests are conducted utilizing an MTS shaking table available at the ENEA Casaccia Laboratory. The main nominal characteristics of the shaking table are frequency range $0-50 \mathrm{~Hz}$, peak acceleration $3 \mathrm{~g}$, maximum displacement $\pm 125 \mathrm{~mm}$, maximum velocity $\pm 0.5 \mathrm{~m} / \mathrm{s}$, and maximum overturning moment about $300 \mathrm{kNm}$.

The structures and the shaking table are instrumented with accelerometers and displacement transducers, Figure 3: 


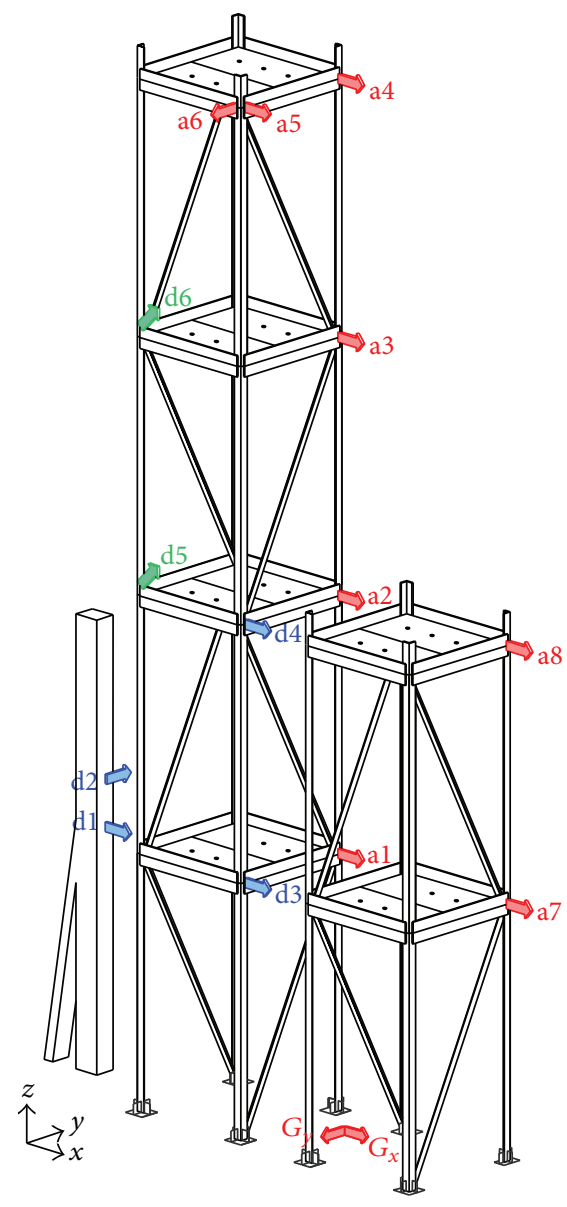

Accelerometers

Laser transducer

LVDT

FIgURE 3: Instrumentation set-up: location and direction.

(i) Accelerometers (PCP Piezotronics 3701G3FA3G): 2 are installed in $x$ and $y$ direction on the table, (sensors $G_{x}$ and $\left.G_{y}\right) ; 6$ are installed on structure A, 5 in $x$ direction (sensors a1-a5) and 1 in $y$ direction (sensor a6); 2 are installed on structure $\mathrm{B}$, in $x$ direction (sensors a7-a8).

(ii) Laser displacement transducers (Microeplison Optoncdl LD1605-200): sensors $\mathrm{d} 1$ and $\mathrm{d} 2$ are assigned to measure relative displacement of the first two levels of structure A, while sensors d 3 and $\mathrm{d} 4$ are used to measure relative displacement between the structures.

(iii) Linear Variable displacement transducers LVDT (Micro Epsilon WDS300P60SRU): sensors d5 and d6 measure interstory displacement for the third and fourth levels of structure A.

A load cell (piezoelectric HBM, $500 \mathrm{Kg}$ ) measures the MR damper control force.

Data achieved are acquired at $500 \mathrm{~Hz}$, using an MTS 469D system.
2.3. Test Program. The physical model is tested under several base excitation time histories at several intensity levels.

A white noise input at low Peak Ground Acceleration (PGA), 0.05-0.1g, and a sine sweep sinusoidal input at frequencies increasing between 1 and $25 \mathrm{~Hz}$ at $0.1 \mathrm{~g}$ are used to dynamically characterize the system. Natural seismic inputs of El Centro, Hachinohe, Kobe, and Northridge earthquakes are used to evaluate the performance of the control strategy [15]. It should be noted that the white noise can be regarded as such in the frequency range of interest for the structures examined, which is approximately $0-25 \mathrm{~Hz}$.

Considering the geometrical scaling factors, a time scaling factor, $\lambda_{T}=1 / \sqrt{\lambda_{L}}=0.447$, and a magnitude scaling factor with PGA levels varying from $0.3 \mathrm{~g}$ to $1 \mathrm{~g}$ are introduced.

Different configurations for the adjacent structures have been considered:

(i) Nonconnected configuration (NC);

(ii) Connected configuration (CC): rigid (RC), passive (PC), and semiactive (SAC).

\section{Identification Procedure and Model Definition}

A general procedure for structural identification and for the definition of a reliable numerical model for adjacent structures connected by MR dampers is proposed making use of the experimental results. Since the approach presented is general, it can be used even for different kinds of control devices.

The method follows three steps: (i) the vibration analysis of the system, (ii) the identification of a first-order modal model (frequencies, damping ratios, and complex eigenvectors), and (iii) the definition of an accurate finite element model (and of the second-order model) by means of an updating procedure.

The procedure is applied at a first stage in the original nonconnected configuration and then in the connected configuration. In the end, an updated finite element model, reliable and suitable for all the examined configurations, is obtained and the mass, damping, and stiffness matrices for a second-order formulation can be supplied.

In the experimentation, the structures were excited with a monodirectional input along the $x$-axis. However it was impossible to fully prevent shaking table acceleration from spilling over to the $y$ direction. Such a component of acceleration influenced in some way the dynamic response and brought out some unexpected natural frequencies. For this reason, in the identification procedure and in the model definition, both base acceleration is, at times, considered.

The ERA/OKID algorithm [24, 25, 29] is utilized to provide an identified first-order representation of the system. The measured bidirectional base acceleration $a_{r}(r=x, y)$ and the structural responses provide data to obtain, after a certain number of calculations, the first-order representation that may be rewritten also in a modal representation. Finally, frequency response functions (FRFs) relating to the two different inputs are obtained. 
3.1. Second-Order Model. The equations of motion for the $N_{i}(i=A, B)$ degree-of-freedom (DOF) coupled structures shown in Figure 1 are

$$
\begin{aligned}
& \mathbf{M} \ddot{\mathbf{x}}(t)+\mathbf{L} \dot{\mathbf{x}}(t)+\mathbf{K x}(t) \\
& =\mathbf{B u}(t)-\mathbf{M} \tau_{x} a_{x}(t)-\mathbf{M} \tau_{y} a_{y}(t) \\
& \mathbf{y}(t) \\
& =\mathbf{C}^{o}\left[\begin{array}{lll}
\mathbf{x}(t) & \dot{\mathbf{x}}(t) & \ddot{\mathbf{x}}(t)
\end{array}\right]+\mathbf{D}_{u}^{o} \mathbf{u}(t)+\mathbf{D}_{x}^{o} a_{x}(t) \\
& +\mathbf{D}_{y}^{o} a_{y}(t) \\
& \mathbf{M}=\left[\begin{array}{cc}
\mathbf{M}_{A} & 0 \\
0 & \mathbf{M}_{B}
\end{array}\right] \text {; } \\
& \mathbf{L}=\left[\begin{array}{cc}
\mathbf{L}_{A} & 0 \\
0 & \mathbf{L}_{B}
\end{array}\right] \text {; } \\
& \mathbf{K}=\left[\begin{array}{cc}
\mathbf{K}_{A} & 0 \\
0 & \mathbf{K}_{B}
\end{array}\right] \text {, }
\end{aligned}
$$

where $\mathbf{x}, \dot{\mathbf{x}}$, and $\ddot{\mathbf{x}}$ are $N \times 1\left(N=N_{A}+N_{B}\right)$, vectors containing structural displacements, velocities, and acceleration; $\mathbf{M}_{i}, \mathbf{L}_{i}$, and $\mathbf{K}_{i}(i=A, B)$ are $N_{i} \times N_{i}$ matrices and represent, respectively, mass, damping, and stiffness matrices; $\mathbf{u}$ is a $N_{u} \times 1$ vector containing control forces with $N_{u}$ number of control devices, while $a_{r}(r=x, y)$ are the ground acceleration. Matrix $\mathbf{B}$, of $N \times N_{u}$ dimensions, and vectors $\boldsymbol{\tau}_{r}$, of $N \times 1$ dimensions, locate the different inputs to the DOF of structures. Finally, y indicates the $N_{m} \times 1$ vector containing the outputs and $\mathbf{C}^{o}$ and $\mathbf{D}_{l}^{o}(l=u, x, y)$ indicate matrices (of proper dimensions) depending on the considered outputs.

3.2. First-Order Model. Equations (1a), (1b), and (1c) may be rewritten in a first-order representation in the continuous time domain as follows:

$$
\begin{aligned}
\dot{\mathbf{z}}(t) & =\mathbf{A} \mathbf{z}(t)+\mathbf{B}_{u} \mathbf{u}(t)-\mathbf{B}_{x} a_{x}(t)-\mathbf{B}_{y} a_{y}(t) \\
\mathbf{y}(t) & =\mathbf{C} \mathbf{z}(t)+\mathbf{D}_{u} \mathbf{u}(t)+\mathbf{D}_{x} a_{x}(t)+\mathbf{D}_{y} a_{y}(t) \\
\mathbf{A} & =\left[\begin{array}{cc}
\mathbf{0} & \mathbf{I} \\
-\mathbf{M}^{-1} \mathbf{K} & -\mathbf{M}^{-1} \mathbf{L}
\end{array}\right], \\
\mathbf{B}_{u} & =\left[\begin{array}{l}
\mathbf{0} \\
\mathbf{B}
\end{array}\right], \\
\mathbf{B}_{x} & =\left[\begin{array}{c}
\mathbf{0} \\
\mathbf{M} \boldsymbol{\tau}_{x}
\end{array}\right], \\
\mathbf{B}_{y} & =\left[\begin{array}{c}
\mathbf{0} \\
\mathbf{M} \boldsymbol{\tau}_{y}
\end{array}\right],
\end{aligned}
$$

where $\mathbf{z}(t)=\left[\begin{array}{ll}\mathbf{x}(t)^{T} & \dot{\mathbf{x}}(t)^{T}\end{array}\right]^{T}$ is the state vector; $\mathbf{C}$ and $\mathbf{D}_{l}$ are related to $\mathbf{C}^{o}$ e $\mathbf{D}_{l}^{o}, l=u, x, y$.

Storing the eigenvalues in the $2 N \times 2 N$ matrix $\Lambda=$ $\operatorname{diag}\left[\begin{array}{llll}\lambda_{1} & \lambda_{2} & \cdots & \lambda_{2 N}\end{array}\right]$, and the corresponding eigenvectors in the $2 N \times 2 N$ matrix $\boldsymbol{\Phi}=\left[\begin{array}{llll}\boldsymbol{\Phi}_{1} & \boldsymbol{\Phi}_{2} & \cdots & \boldsymbol{\Phi}_{2 N}\end{array}\right]$. Eqs. (2a) and (2b) can be expressed in the modal representation, using a new variable $\mathbf{z}(t)=\boldsymbol{\Phi} \xi(t), \boldsymbol{\Phi}=\left[\boldsymbol{\varphi}^{T}(\boldsymbol{\varphi} \boldsymbol{\Lambda})^{T}\right]^{T}$; see [30]:

$$
\begin{aligned}
\dot{\xi}(t)= & \Lambda \xi(t)+\Phi^{-1} \mathbf{B}_{u} \mathbf{u}(t)-\Phi^{-1} \mathbf{B}_{x} a_{x}(t) \\
& -\Phi^{-1} \mathbf{B}_{y} a_{y}(t) \\
\mathbf{y}(t)= & \mathbf{C} \boldsymbol{\Phi} \xi(t)+\mathbf{D}_{u} \mathbf{u}(t)+\mathbf{D}_{x} a_{x}(t)+\mathbf{D}_{y} a_{y}(t) .
\end{aligned}
$$

The structural outputs can be related to the inputs by applying the Laplace transformation (indicated with the symbol $\widetilde{\cdot}(s)$ ) and using (3a) and (3b):

$$
\begin{aligned}
\widetilde{\mathbf{y}}(s) & =\mathbf{H}_{u}(s) \widetilde{\mathbf{u}}(s)-\mathbf{H}_{x}(s) \tilde{a}_{x}(s)-\mathbf{H}_{y}(s) \tilde{a}_{y}(s) \\
\mathbf{H}_{u}(s) & =\mathbf{C} \boldsymbol{\Phi}[s \mathbf{I}-\boldsymbol{\Lambda}]^{-1} \boldsymbol{\Phi}^{-1} \mathbf{B}_{u} \\
\mathbf{H}_{r}(s) & =\mathbf{C} \boldsymbol{\Phi}[s \mathbf{I}-\boldsymbol{\Lambda}]^{-1} \boldsymbol{\Phi}^{-1} \mathbf{B}_{r}, \quad r=x, y,
\end{aligned}
$$

where $s$ indicates the Laplace variable and $\mathbf{H}_{l}(s),(l=u, x, y)$ are the frequency response functions (FRFs). In (4a) terms related to matrix $\mathbf{D}_{l}(l=u, x, y)$ are not considered.

Equations (4a), (4b), and (4c) can also be expressed as in $[31,32]$ :

$$
\begin{aligned}
& H_{u i j}(s) \\
& =\sum_{k=1}^{n} \frac{\left(\varphi_{i k} \varphi_{k j}+\varphi_{i k}^{*} \varphi_{k j}^{*}\right) s+\left(\varphi_{i k} \lambda_{k}^{*} \varphi_{k j}+\varphi_{i k}^{*} \lambda_{k} \varphi_{k j}^{*}\right)}{s^{2}-\left(\lambda_{k}+\lambda_{k}^{*}\right) s+\lambda_{k} \lambda_{k}^{*}} \\
& H_{r i}(s) \\
& =\sum_{k=1}^{n} \frac{\left(\varphi_{i k} Q_{r k}+\varphi_{i k}^{*} Q_{r k}^{*}\right) s+\left(\varphi_{i k} \lambda_{k}^{*} Q_{r k}+\varphi_{i k}^{*} \lambda_{k} Q_{r k}^{*}\right)}{s^{2}-\left(\lambda_{k}+\lambda_{k}^{*}\right) s+\lambda_{k} \lambda_{k}^{*}},
\end{aligned}
$$

where $k$ indicates the considered mode and $i$ and $j$ indicate, respectively, the DOF where the output is measured and the DOF where the input is applied; finally, $(*)$ indicates the complex conjugate. Examining the FRFs concerning the seismic excitation (5b), the following equalities have been demonstrated in [32], for a classically damped structure:

$$
\begin{gathered}
\varphi_{i k} \lambda_{k}^{*} Q_{r k}+\varphi_{i k}^{*} \lambda_{k} Q_{r k}^{*}=\theta_{r i k}=\varphi_{i k} p_{r k} \\
\varphi_{i k} Q_{r k}+\varphi_{i k}^{*} Q_{r k}^{*}=0 .
\end{gathered}
$$

Eq. (6a) defines the seismic eigenvectors components $\theta_{\text {rik }}$ $[33,34] ; p_{r k}=\boldsymbol{\varphi}_{k}^{T} \mathbf{M} \tau_{r} / \boldsymbol{\varphi}_{k}^{T} \mathbf{M} \boldsymbol{\varphi}_{k}(r=x, y)$ indicates the modal participation factor, while $\varphi_{k}$ are the natural eigenvectors of the second-order model. It is important to observe that the seismic eigenvectors are defined independently of the way the system eigenvectors are scaled: they provide information about the system properties.

For each structure, the considered DOFs at each level are the center of mass translation $u$ and $v$ in the $x$ and $y$ directions and the rotation $\theta$ about the $z$ direction, Figure 2(b). Consequently $N_{A}=12$ and $N_{B}=6$. In the nonconnected configuration, the structures move independently, so $N_{u}=0$. In the connected configuration, the structures are linked at the second level by the MR damper so $N_{u}=1$. 
3.3. MR Damper Model. It is known that an MR damper subjected to harmonic excitation at a given level of input voltage manifests viscoplastic behavior [15]. A reliable model able to reproduce such mechanical behavior is represented by the modified Bouc-Wen model [35], which is utilized in this paper to simulate the MR damper control force. The model, originally developed in [36], is schematically represented in Figure 2(c). The force $u$ can be expressed as follows:

$$
u(t, V, \delta, \dot{\delta})=\frac{F_{y}(V)}{\delta_{y}} \zeta+C_{0}(V) \dot{\delta}+K_{0}\left(\delta-\delta_{0}\right)
$$

where $V$ is the input voltage imposed on the device, $\delta_{0}$ is the initial deformation, and $\zeta(t)$ is an auxiliary variable related to the deformation $\delta(t)=x_{B 2}(t)-x_{A 2}(t)$ through the following equation:

$$
\dot{\zeta}(t)=\dot{\delta} \cdot\left(\bar{A}-\bar{\beta} \cdot|\zeta|^{n}-\bar{\gamma} \cdot \operatorname{sgn}(\dot{\delta}) \cdot \zeta \cdot|\zeta|^{n-1}\right) .
$$

Assigning $\bar{A}=A \delta_{y}=1$ and $\bar{\beta}+\bar{\gamma}=\beta \delta_{y}+\gamma \delta_{y}=1, F_{y}$ and $\delta_{y}$ represent the yielding force and the yielding deformation, $C_{0}$ is the damping coefficient, and $K_{0}$ is the linear spring stiffness.

For MR devices, the parameter which can be directly regulated in order to change the control force intensity is the input voltage $(V)$ in the range of variation $V=\left[V_{\min }=\right.$ $\left.0, V_{\max }\right]$. In the passive case, the voltage remains constant, whereas in the semiactive case it may vary among several states following an established control law. In the semiactive case, the input voltage has been changed in accordance with a local ON-OFF control algorithm based on the Lyapunov stability theory. See for details [15]. In the adopted mechanical model, $F_{y}$ and $C_{0}$ are the only quantities varying with the input voltage $V$.

\section{Study of the Nonconnected Configuration (NC)}

In the nonconnected configuration, the adjacent structures move independently. The section is organized following the three steps described in Section 3. In the end, numerical and experimental outcomes will be compared to assess the feasibility of the model.

Among all the records achieved by sensors represented in Figure 3, acceleration measured by sensors al-a8 is considered the most reliable and will be used in further analysis $\left(N_{m}=8\right)$.

4.1. Vibration Analysis. The first test examined is the sine sweep at PGA $0.1 \mathrm{~g}$ with a frequency range of $1-25 \mathrm{~Hz}$ and a sweep rate of $0.20 \mathrm{~Hz} / \mathrm{sec}$. By considering the acceleration recorded by sensors al-a5 installed on structure $\mathrm{A}$ in the $x$ direction, Figure 4 , four natural frequencies appear clearly at about 2.7, 8.1, 13.3, and $17 \mathrm{~Hz}$. It should be noted that resonant frequency around $8.3 \mathrm{~Hz}$ does not appear for sensor a3: this position represents therefore a vibratory node. The acceleration recorded by sensor a6, installed at the fourth floor in the $y$ direction, detects resonances at about 8.3 and $12.5 \mathrm{~Hz}$, and smaller amplitudes are observed with respect to the acceleration measured in $x$ direction by sensors al-a5.

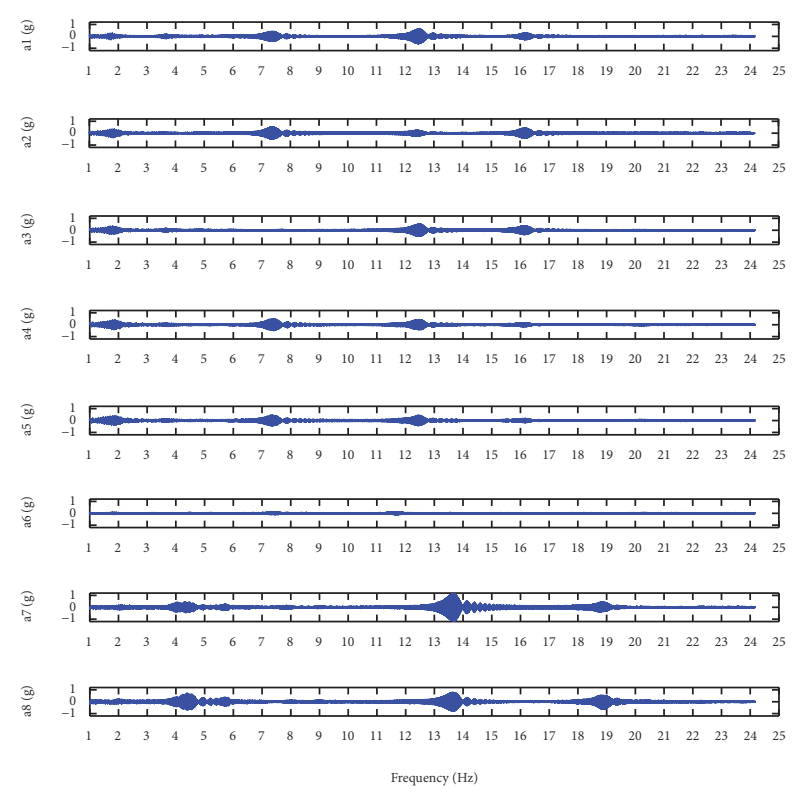

FIGURE 4: Nonconnected (NC) configuration, acceleration measured by sensors a1-a8. Sine sweep frequency test PGA $0.1 \mathrm{~g}$.

Sensors a7 and a8 detected three natural frequencies at about 5.1, 14.5 , and $19.8 \mathrm{~Hz}$ for Structure B.

4.2. Identification of the First-Order Model. The identification procedure has been performed to obtain modal parameters for the structures.

Figures 5(a) and 5(b) show the identified FRFs $\mathbf{H}_{r}(r=$ $x, y$ ) obtained using data recorded during the white noise test with PGA $0.1 \mathrm{~g}$, considering ground acceleration in $x$ and $y$ direction, respectively. The identified FRFs $\mathbf{H}_{x}$ for structure A, corresponding to sensors al-a6 in Figure 5(a), show four resonant frequencies at about 2.7, 8.15, 13.18, and $16.85 \mathrm{~Hz}$. Also for sensor a6, the identified FRF shows a sole amplification at about $8.15 \mathrm{~Hz}$, in conformity with the experimental one. In accordance with this evidence, the acceleration in the $y z$ plane, due to the base excitation in the $y$ direction is reasonably negligible. The identified FRFs $\mathbf{H}_{y}$ in Figure 5(b) show lower amplifications when compared with the ones related to the base excitation in $x$ direction, at the same frequencies. For sensors al-a5 the amplifications highlight the same first three natural frequencies but with lower amplitudes, while only a light amplification around $8.15 \mathrm{~Hz}$ is observed for sensor a6. The identified FRFs $\mathbf{H}_{x}$ for structure B, corresponding to sensors a7 and a8 in Figure 5(a), show three natural frequencies at about 5.25, 14.43, and 19.66 Hz. The identified FRFs $\mathbf{H}_{y}$ in Figure 5(b) show lower amplifications when compared with the ones related to the base excitation in $x$ direction at the same frequencies. Only the last frequency, about $19.66 \mathrm{~Hz}$, is more evident.

As a matter of fact, the results obtained by observing the identified FRFs suggest a fundamentally planar dynamic behavior for the structures: acceleration recorded in the $x$ direction is strictly related to the excitation in the same direction. The frequency observed for structure A at about 
TABLE 1: Nonconnected (NC) configuration. Structures A and B identified frequencies and damping factors versus PGA.

\begin{tabular}{|c|c|c|c|c|c|c|c|c|}
\hline Mode & 1 & 2 & 3 & 4 & 1 & 2 & 3 & 4 \\
\hline PGA & \multicolumn{4}{|c|}{ Frequency $(\mathrm{Hz})$} & \multicolumn{4}{|c|}{ Damping factor (\%) } \\
\hline \multicolumn{9}{|c|}{ Structure A } \\
\hline $0.05 \mathrm{~g}$ & 2.73 & 8.22 & 13.30 & 17.08 & 0.70 & 0.65 & 0.67 & 0.85 \\
\hline $0.10 \mathrm{~g}$ & 2.70 & 8.15 & 13.18 & 16.85 & 2.29 & 1.05 & 0.98 & 1.12 \\
\hline $0.30 \mathrm{~g}$ & 2.54 & 7.95 & 12.90 & 16.54 & 6.80 & 1.86 & 1.75 & 2.57 \\
\hline \multicolumn{9}{|c|}{ Structure B } \\
\hline $0.05 \mathrm{~g}$ & 5.28 & 14.49 & 19.70 & & 0.38 & 0.35 & 0.32 & \\
\hline $0.10 \mathrm{~g}$ & 5.25 & 14.43 & 19.66 & & 0.75 & 0.53 & 0.41 & \\
\hline $0.30 \mathrm{~g}$ & 5.10 & 14.30 & 19.40 & & 2.53 & 0.82 & 0.62 & \\
\hline
\end{tabular}

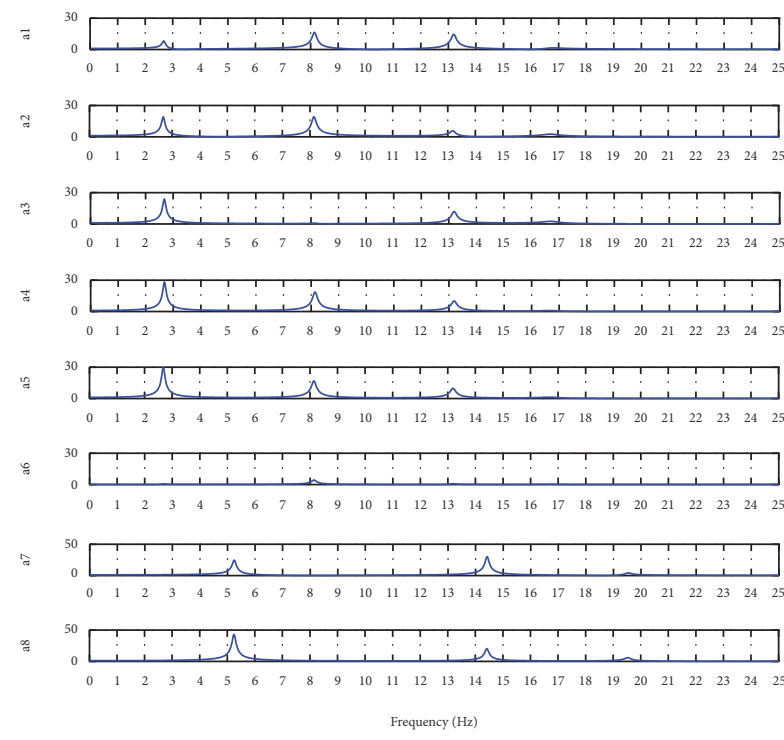

(a)

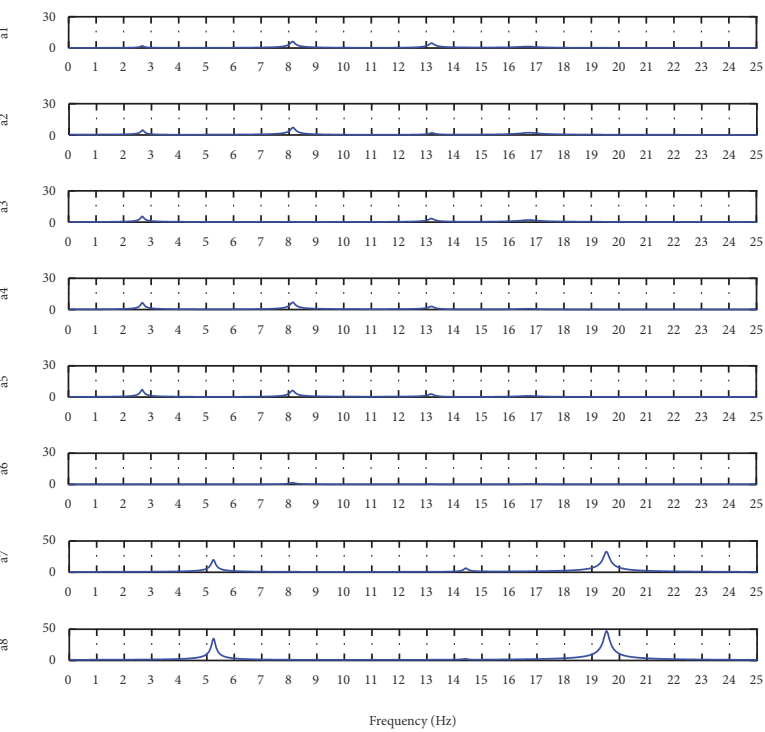

(b)

FIGURE 5: Nonconnected (NC) configuration, identified frequency response functions: (a) sensors al-a8 versus ground acceleration $x$ direction; (b) sensors al-a8 versus ground acceleration $y$ direction. White noise test PGA $0.1 \mathrm{~g}$.

$8 \mathrm{~Hz}$ highlights a mode which has components in the $y$ direction as well. Since the excitation in $y$ direction was lower than the excitation in $x$ direction and the amplification measured by sensor a6 was very low compared to those detected by sensors a1-a5, only information obtained with excitation in $x$ direction is considered in the following.

Once the $\lambda_{i}$ eigenvalues have been identified, system frequencies and damping factors are evaluated [32]. Both the tests with a low PGA (white noise at $0.05-0.1 \mathrm{~g}$ ) and a test with a higher PGA (Kobe at $0.3 \mathrm{~g}$ ) are considered. Table 1 contains the identified frequencies and damping factors for both structures at different PGA levels. Concerning frequencies of both structures, by comparing values identified at different PGA, a general trend becomes evident: they decrease by increasing PGA. This fact can be interpreted as a not perfectly linear structural behavior (probably due to bolted connections). For structure A, the first frequency decreases from $2.74 \mathrm{~Hz}$ at $0.05 \mathrm{~g}$ PGA to $2.54 \mathrm{~Hz}$ at $0.3 \mathrm{~g}$, with a difference of $6 \%$. Frequencies of higher modes have a lower variation with respect to the base excitation level (2-3\%). For structure B, the maximum frequency shift (around 3\%) occurs in the fundamental frequency, while other frequencies show a shift of approximately $1 \%$.

PGA level influences damping ratio as well. Considering all the identified modes, it is possible to state that damping ratios increase by increasing PGA. Besides, it is possible to notice that the modal characteristics identified for structure A are more influenced by the PGA level than those identified for structure B. For the sake of exemplification, let us observe the damping ratio of the first mode. For structure $A$, it increases from $0.70 \%$ at $0.05 \mathrm{~g}$ to $6.80 \%$ at $0.3 \mathrm{~g}$; for structure $\mathrm{B}$, it increases from $0.38 \%$ to $2.53 \%$.

Seismic eigenvectors, estimated with (6a) and (6b), are identified by considering the white noise test at $0.1 \mathrm{~g}$ and the Kobe earthquake test at $0.3 \mathrm{~g}$. Tables 2 and 3 contain seismic eigenvectors identified for structures $\mathrm{A}$ and $\mathrm{B}$, respectively.

By observing the identified values, it is possible to make the following considerations:

(1) Seismic eigenvectors were evaluated through (6a). The quantity in (6b) turned out to be close to zero 
TABLE 2: Structure A identified seismic eigenvectors, white noise test at $0.1 \mathrm{~g}$; Kobe test PGA $0.3 \mathrm{~g}$.

\begin{tabular}{|c|c|c|c|c|c|c|c|c|}
\hline Mode & 1 & 2 & 3 & 4 & 1 & 2 & 3 & 4 \\
\hline Location & \multicolumn{4}{|c|}{$x$-direction } & \multicolumn{4}{|c|}{$y$-direction } \\
\hline & \multicolumn{8}{|c|}{ Test white noise PGA $0.10 \mathrm{~g}$} \\
\hline al & -0.33 & -0.34 & -0.21 & -0.05 & -0.15 & -0.10 & 0.006 & 0.016 \\
\hline a2 & -0.80 & -0.39 & 0.08 & 0.09 & -0.38 & -0.12 & -0.002 & -0.023 \\
\hline a3 & -1.00 & 0.01 & 0.17 & -0.08 & -0.48 & 0.00 & -0.004 & 0.020 \\
\hline $\mathrm{a} 4$ & -1.18 & 0.38 & -0.14 & 0.03 & -0.57 & 0.11 & 0.003 & -0.009 \\
\hline a5 & -1.27 & 0.34 & -0.14 & 0.04 & -0.61 & 0.10 & 0.004 & -0.010 \\
\hline \multirow[t]{2}{*}{ a6 } & 0.02 & -0.08 & -0.01 & 0.00 & 0.01 & -0.02 & 0.000 & -0.001 \\
\hline & \multicolumn{8}{|c|}{ Test Kobe PGA $0.30 \mathrm{~g}$} \\
\hline al & -0.35 & -0.29 & -0.20 & -0.02 & -0.07 & -0.30 & -0.14 & -0.01 \\
\hline a2 & -0.86 & -0.36 & 0.08 & 0.03 & -0.16 & -0.37 & 0.06 & 0.02 \\
\hline a3 & -1.06 & 0.02 & 0.15 & -0.04 & -0.20 & 0.06 & 0.10 & 0.00 \\
\hline $\mathrm{a} 4$ & -1.24 & 0.36 & -0.14 & 0.01 & -0.23 & 0.40 & -0.09 & 0.04 \\
\hline a5 & -1.34 & 0.30 & -0.13 & 0.02 & -0.25 & 0.29 & -0.09 & 0.01 \\
\hline a6 & 0.02 & -0.10 & -0.01 & 0.01 & 0.00 & -0.16 & -0.01 & 0.00 \\
\hline
\end{tabular}

TABLE 3: Structure B identified seismic eigenvectors, white noise test at $0.1 \mathrm{~g}$; Kobe test PGA $0.3 \mathrm{~g}$.

\begin{tabular}{|c|c|c|c|c|c|c|}
\hline Mode & 1 & 2 & 3 & 1 & 2 & 3 \\
\hline Location & & $x$-direction & & \multicolumn{3}{|c|}{$y$-direction } \\
\hline & \multicolumn{6}{|c|}{ Test white noise PGA $0.10 \mathrm{~g}$} \\
\hline a7 & 0.70 & 0.30 & 0.02 & 0.001 & -0.05 & 0.26 \\
\hline a8 & 1.22 & -0.21 & 0.02 & 0.003 & 0.03 & 0.41 \\
\hline & \multicolumn{6}{|c|}{ Test Kobe PGA $0.30 \mathrm{~g}$} \\
\hline a7 & 0.66 & 0.23 & 0.01 & 0.03 & -0.01 & 0.25 \\
\hline a8 & 1.18 & -0.16 & 0.01 & 0.07 & -0.01 & 0.37 \\
\hline
\end{tabular}

and the error in neglecting this term is about $5 \%$. This means that the system is, with a good approximation, a classically damped system.

(2) Comparing the seismic eigenvectors in $x$ direction identified through the various tests at different PGA, a good agreement is generally observed for the shapes. Comparing the significant components of each eigenvector (with values in the order of $10^{-1}$ ) relative differences are in the range of $5-24 \%$.

(3) Seismic eigenvectors components corresponding to sensors a1-a5 have higher values when compared to the components relating to sensor a6.

(4) Seismic eigenvectors in $y$ direction for the different tests are generally well identified in the shape; however by comparing the significant components of each eigenvector the differences can be substantial.

(5) Compared to those in $y$ direction, seismic eigenvectors in $x$ direction show a lower degree of variation with the excitation considered: the maximum variation of vector's components for different tests is about $20 \%$.

(6) Seismic eigenvectors in $y$ direction appear more sensitive to the PGA level than those in $x$ direction.
Once modal parameters have been identified (frequencies, damping ratios, and seismic eigenvectors), the FE model can be defined and, then, the second-order model representation can be provided. The model should be suitable for the NC configuration, as well as for the controlled configuration. Considering that in the controlled configuration the tests have been performed with relative higher PGA levels (greater or equal to $0.3 \mathrm{~g}$ ) than in the NC configuration, the modal quantities identified for the Kobe test with $0.3 \mathrm{~g}$ will be used in the further analysis.

4.3. FE Model and Updating Procedure: Numerical-Experimental Comparison. The structures shown in Figure 1 are modeled using a three-dimensional FE model (COMSOL Multiphysics 3.2).

Since not all the parameters involved in the model are considered exactly defined, some of them are considered variable and a model updating procedure is applied to select their optimal values. By perturbing the values assumed for the parameters that are uncertain, a more representative model is obtained.

Columns, beams, and bracings are modeled with threedimensional beam elements. Geometry and masses are considered known, Figures 2(a) and 2(b). The mass distribution, for each considered DOF has the following values: structures $\mathrm{A}$ and $\mathrm{B}$ translational mass in $x$ and $y$ direction is equal 
for each floor $m_{x}=m_{y}=132.34 \mathrm{~kg}$, apart from the top floor of each structure, which has the value of $m_{x}=m_{y}=$ $123.36 \mathrm{~kg}$. Structures A and B rotational inertia is equal for each floor $I_{\theta}=30.78 \mathrm{~kg} \cdot \mathrm{m}^{2}$ except for the top floor of each structure which has the value $I_{\theta}=22.07 \mathrm{~kg} \cdot \mathrm{m}^{2}$. The major uncertainty lies in modeling the bolted connections. In fact, constraints between the structures and the shaking table are not well defined, and it is not accurate to model the columns as perfectly clamped. Since for none of them the base constraint avoids rotations around $x$ - and $y$-axes, rotational springs have been inserted. The rigidity $K_{r i}$, with $r=1-4$ and $i=A, B$, is different for each column, but is the same in both directions.
In addition, connections between columns and other structural components are bolted. In order to consider this aspect, different Young's moduli $E_{r i}$, with $r=1-4$ for structure $\mathrm{A}$ and $r=1,2$ for structure $\mathrm{B}$, are considered at each level. As a result, a total number of 8 and 6 variable parameters are assumed for structures A and B, respectively.

The procedure of model updating is based on the minimization of the following error function [37]:

$$
\mathbf{e}\left(K_{r i}, E_{r i}\right)=(\boldsymbol{\alpha}-\widetilde{\boldsymbol{\alpha}})
$$

which measures the difference between numerical $\boldsymbol{\alpha}$ and experimental identified quantities $\widetilde{\boldsymbol{\alpha}}$. Vector $\boldsymbol{\alpha}$ collects

$$
\boldsymbol{\alpha}=\left[\begin{array}{lllllllllllll}
f_{1} & f_{2} & \cdots & f_{n} & \boldsymbol{\theta}_{1}^{T} & \boldsymbol{\theta}_{2}^{T} & \cdots & \boldsymbol{\theta}_{n}^{T} & \mathrm{MAC}_{1} & \mathrm{MAC}_{2} & \cdots & \mathrm{MAC}_{n}
\end{array}\right]^{T},
$$

where $f_{i}$ are the system's frequencies and $\boldsymbol{\theta}_{i}$ the corresponding seismic eigenvectors, whereas $\mathrm{MAC}_{i}$ are the Modal Assurance Criterion (MAC) indexes that define the degree of correlation between the considered seismic eigenvector and the corresponding identified one. Finally, $n$ is the number of the identified modes which are considered meaningful.

It is important to underline that using seismic eigenvectors is possible in order to directly relate the identified components and the calculated ones. In fact, seismic eigenvectors, differently from natural eigenvectors, are not related to the system representation and do not depend on any assumed normalization, but they are only related to the system properties [33, 34].

The optimal values for the uncertain parameters $\left(K_{r i}\right.$ and $\left.E_{r i}\right)$ are given minimizing the weighted penalty function:

$$
\mathbf{J}=\mathbf{e}\left(K_{r i}, E_{r i}\right)^{T} \mathbf{W e}\left(K_{r i}, E_{r i}\right),
$$

where $\mathbf{W}$ is a proper dimension diagonal matrix, containing weights, $w_{i}$, for the different quantities; such weights are defined as $w_{i}=q_{i} /\left\|\widetilde{\alpha}_{i}\right\|$ and are used to consider the identified modal quantities $\widetilde{\alpha}_{i}$ and their reliability level $q_{i}$, [38]. Moreover, in order to improve the convergence, a GaussNewton method was utilized with a trust region algorithm.

Concerning the identified frequencies and seismic eigenvectors, the values related to base excitation in the $x$ direction have been considered to define the error function (see Tables 1-3). Corresponding MAC indexes are calculated, neglecting the component corresponding to sensor a6, placed in the $y$ direction on structure A. The identified frequencies are considered more reliable than MAC indexes, so their weight in (11) is increased considering for $q_{i}$ a value 10 times higher than the value assumed for the eigenvectors. Besides, it is important to note that in the error function e, (9), the number of equations is higher than the number of unknowns.

Table 4 shows the initial and updated values for the variable parameters $K_{r i}$ and $E_{r i}$. Frequencies calculated using the initial and updated FE model and the experimental identified ones are shown in Table 5. The maximum error for the updated model is $1 \%$. Corresponding MAC indexes for each structure are all close to 1 for all modes, indicating that the correlation between numerical and identified seismic eigenvectors is high. Numerical seismic eigenvectors with the updated model relative to the base excitation in $x$ direction are reported in Table 6. By comparing numerical with experimentally identified eigenvectors (Tables 2 and 3, Kobe earthquake test), maximum error between numerical and experimentally identified eigenvectors is around the $20 \%$ for structure A and 13\% for structure B. Other components have errors up to $5 \%$. The only exception is a significant error of about $50 \%$ found for the second mode at the location of sensor a3; this is because this sensor is located in a vibratory node.

The updated FE model seems feasible; it is therefore possible to obtain the stiffness matrices to be used in the secondorder model. Tables 7 and 8 show the stiffness matrices for structures A and B, respectively. Once the mass distribution values are known, the mass and damping matrices can be easily derived assuming as damping factors values reported in Table 1 for the identified modes and the value $1 \%$ for the not identified ones.

Tables 9 and 10 show all the FE model frequencies and the excited masses for structures A and B, respectively. By observing the results obtained with the FE model, some aspects that emerged from the vibration analysis can be better explained. It can be observed that the modes are lightly coupled due to the braces placed on the structures. In fact, the structures are not perfectly symmetric in $x$ and $y$ directions. Concerning structure A, Table 9, only the translational models in $x$ direction were experimentally identified (modes 1, 3, 5, and 6). The first mode has $90 \%$ of excited mass in $x$ direction. The third mode highlights a significant excited mass in the $x$ direction; however, a low percentage of mass is excited in the $y$ direction as well. In the vibration analysis, it was observed that the acceleration recorded by sensor a6, placed in $y$ direction on structure A, during the sine sweep test, showed a resonance at about $8.1 \mathrm{~Hz}$ (Figure 4). Therefore, the third mode can be basically considered a bending mode in the $x$ direction, but, due 
TABLE 4: Initial and updated values of FE model parameters.

\begin{tabular}{lcccccccc}
\hline & $\begin{array}{c}K r_{1} \\
(\mathrm{Nm} / \mathrm{rad})\end{array}$ & $\begin{array}{c}K r_{2} \\
(\mathrm{Nm} / \mathrm{rad})\end{array}$ & $\begin{array}{c}K r_{3} \\
(\mathrm{Nm} / \mathrm{rad})\end{array}$ & $\begin{array}{c}K r_{4} \\
(\mathrm{Nm} / \mathrm{rad})\end{array}$ & $\begin{array}{c}E_{1} \\
\left(\mathrm{~N} / \mathrm{m}^{2}\right)\end{array}$ & $\begin{array}{c}E_{2} \\
\left(\mathrm{~N} / \mathrm{m}^{2}\right)\end{array}$ & $\begin{array}{c}E_{3} \\
\left(\mathrm{~N} / \mathrm{m}^{2}\right)\end{array}$ & $\begin{array}{c}E_{4} \\
\left(\mathrm{~N} / \mathrm{m}^{2}\right)\end{array}$ \\
\hline $\begin{array}{l}\text { Structure A } \\
\quad \text { Initial value }\end{array}$ & $1.0 \cdot 10^{6}$ & $1.0 \cdot 10^{6}$ & $1.0 \cdot 10^{6}$ & $1.0 \cdot 10^{6}$ & $2.0 \cdot 10^{11}$ & $2.0 \cdot 10^{11}$ & $2.0 \cdot 10^{11}$ & $2.0 \cdot 10^{11}$ \\
$\quad \begin{array}{l}\text { Updated value } \\
\text { Structure B }\end{array}$ & $4.3 \cdot 10^{6}$ & $3.2 \cdot 10^{6}$ & $4.5 \cdot 10^{6}$ & $3.3 \cdot 10^{6}$ & $1.8 \cdot 10^{11}$ & $1.9 \cdot 10^{11}$ & $2.9 \cdot 10^{11}$ & $2.3 \cdot 10^{11}$ \\
$\quad \begin{array}{l}\text { Initial value } \\
\text { Updated value }\end{array}$ & $1.0 \cdot 10^{5}$ & $1.0 \cdot 10^{5}$ & $1.0 \cdot 10^{5}$ & $1.0 \cdot 10^{5}$ & $2.0 \cdot 10^{11}$ & $2.0 \cdot 10^{11}$ & - \\
\hline
\end{tabular}

TABLE 5: Initial and updated FE model frequencies.

\begin{tabular}{|c|c|c|c|c|c|}
\hline & Initial value & Updated value & Identified value & Initial error (\%) & Updated error (\%) \\
\hline \multicolumn{6}{|l|}{ Structure A } \\
\hline$f_{1}(\mathrm{~Hz})$ & 2.64 & 2.59 & 2.54 & 3.94 & 0.79 \\
\hline$f_{2}(\mathrm{~Hz})$ & 7.70 & 7.94 & 7.95 & 3.14 & 0.38 \\
\hline$f_{3}(\mathrm{~Hz})$ & 12.19 & 12.66 & 12.90 & 5.50 & 1.01 \\
\hline$f_{4}(\mathrm{~Hz})$ & 15.21 & 16.80 & 16.54 & 8.04 & 1.09 \\
\hline \multicolumn{6}{|l|}{ Structure B } \\
\hline$f_{1}(\mathrm{~Hz})$ & 4.84 & 5.07 & 5.10 & 4.51 & 0.60 \\
\hline$f_{2}(\mathrm{~Hz})$ & 12.80 & 14.30 & 14.30 & 10.48 & 0.00 \\
\hline
\end{tabular}

TABLE 6: Structure A and B FE model seismic eigenvectors.

\begin{tabular}{|c|c|c|c|c|}
\hline Mode & 1 & 2 & 3 & 4 \\
\hline Location & \multicolumn{4}{|c|}{$x$ direction } \\
\hline al & -0.44 & -0.33 & -0.21 & -0.02 \\
\hline a2 & -0.85 & -0.29 & 0.10 & 0.03 \\
\hline a3 & -1.08 & 0.02 & 0.14 & -0.04 \\
\hline a4 & -1.25 & 0.35 & -0.12 & 0.02 \\
\hline a5 & -1.25 & 0.35 & -0.12 & 0.02 \\
\hline a7 & 0.77 & 0.23 & & \\
\hline a8 & 1.17 & -0.16 & & \\
\hline
\end{tabular}

TABle 7: Structure A stiffness matrix $\left(\cdot 10^{5}\right) \mathrm{N} / \mathrm{m}$.

\begin{tabular}{lccccccccccc}
\hline 6.17 & -0.71 & 0.00 & -3.25 & 0.36 & 0.00 & 0.17 & 0.01 & 0.00 & 0.04 & -0.05 & 0.00 \\
-0.71 & 174.38 & 0.00 & -1.10 & -94.81 & 0.00 & 0.53 & 5.81 & 0.00 & 1.66 & 8.84 & 0.00 \\
0.00 & 0.00 & 16.03 & 0.00 & 0.00 & -8.60 & 0.00 & 0.00 & 0.43 & 0.00 & 0.00 & 0.73 \\
-3.25 & -1.10 & 0.00 & 7.67 & 1.12 & 0.00 & -4.77 & -0.40 & 0.00 & 0.26 & 0.00 & 0.00 \\
0.36 & -94.81 & 0.00 & 1.12 & 173.94 & 0.00 & -0.01 & -100.25 & 0.00 & -1.46 & 15.13 & 0.00 \\
0.00 & 0.00 & -8.60 & 0.00 & 0.00 & 16.33 & 0.00 & 0.00 & -9.38 & 0.00 & 0.00 & 1.22 \\
0.17 & 0.53 & 0.00 & -4.77 & -0.01 & 0.00 & 8.14 & -0.59 & 0.00 & -3.54 & 0.34 & 0.00 \\
0.01 & 5.81 & 0.00 & -0.40 & -100.25 & 0.00 & -0.59 & 172.42 & 0.00 & 0.96 & -79.37 & 0.00 \\
0.00 & 0.00 & 0.43 & 0.00 & 0.00 & -9.38 & 0.00 & 0.00 & 16.33 & 0.00 & 0.00 & -7.52 \\
0.04 & 1.66 & 0.00 & 0.26 & -1.46 & 0.00 & -3.54 & 0.96 & 0.00 & 3.22 & -0.31 & 0.00 \\
-0.05 & 8.84 & 0.00 & 0.00 & 15.13 & 0.00 & 0.34 & -79.37 & 0.00 & -0.31 & 52.01 & 0.00 \\
0.00 & 0.00 & 0.73 & 0.00 & 0.00 & 1.22 & 0.00 & 0.00 & -7.52 & 0.00 & 0.00 & 5.29 \\
\hline
\end{tabular}


TABle 8: Structure B stiffness matrix B $\left(\cdot 10^{5}\right) \mathrm{N} / \mathrm{m}$.

\begin{tabular}{lccccc}
\hline 7.73 & -1.04 & -0.01 & -4.20 & 0.38 & -74.49 \\
-1.04 & 174.93 & 0.10 & 1.46 & -0.04 & -0.04 \\
-0.01 & 0.10 & 16.51 & 0.00 & -0.43 & 0.00 \\
-4.20 & 1.46 & 0.00 & 4.02 & 59.70 & 0.03 \\
0.38 & -74.49 & -0.04 & -0.43 & 0.03 \\
0.00 & -0.04 & -7.27 & 0.00 & 6.05 \\
\hline
\end{tabular}

TABLE 9: Structure A FE model frequencies and excited masses.

\begin{tabular}{|c|c|c|c|c|c|c|c|c|c|c|c|c|}
\hline Mode & 1 & 2 & 3 & 4 & 5 & 6 & 7 & 8 & 9 & 10 & 11 & 12 \\
\hline Frequency $(\mathrm{Hz})$ & 2.56 & 6.52 & 7.98 & 8.18 & 12.77 & 16.72 & 22.34 & 32.59 & 39.65 & 50.40 & 61.15 & 79.08 \\
\hline$\% \operatorname{dir} X$ & 90.02 & 0.00 & 7.68 & 0.02 & 2.18 & 0.09 & 0.00 & 0.00 & 0.00 & 0.00 & 0.00 & 0.00 \\
\hline$\% \operatorname{dir} Y$ & 0.01 & 0.00 & 0.49 & 75.87 & 0.00 & 0.00 & 0.00 & 20.18 & 0.00 & 0.00 & 2.99 & 0.47 \\
\hline$\%$ Rot. & 0.00 & 80.73 & 0.00 & 0.00 & 0.00 & 0.00 & 17.24 & 0.00 & 2.78 & 0.37 & 0.00 & 0.00 \\
\hline
\end{tabular}

TABLE 10: Structure B FE model frequencies and excited masses.

\begin{tabular}{lcccccc}
\hline Mode & 1 & 2 & 3 & 4 & 5 & 5 \\
\hline Frequency $(\mathrm{Hz})$ & 5.07 & 14.30 & 20.69 & 21.66 & 42.52 & 64.11 \\
\% dir $X$ & 95.85 & 4.15 & 0.00 & 0.00 & 0.00 & 0.00 \\
\% dir $Y$ & 0.01 & 0.04 & 0.00 & 89.51 & 0.00 & 10.45 \\
\% Rot. & 0.00 & 0.00 & 91.14 & 0.00 & 8.90 & 0.00 \\
\hline
\end{tabular}

to the small percentage of mass excited in the $y$ direction, a modest amplification was detected by sensor a6 as well. Concerning structure B, Table 10, the first and second modes are translational in $x$ direction, whereas the third is torsional. All of them were well identified. The identified frequency at $19.40 \mathrm{~Hz}$, close to the value estimated with the FE model $20.69 \mathrm{~Hz}$, could therefore correspond to a torsional mode. In conclusion, it can be stated that there was a satisfactory agreement between experimentally identified and selected numerical modes: the identification procedure and the FE model were validated. As a result, for both structures, even modes with a low percentage of excited mass in the $x$ direction were assessed through the identification procedure.

\section{Study of the Connected Configuration (CC)}

In the connected configuration structures interact reciprocally, influenced by the control action of the MR damper installed between them. It is important to underline that, in this configuration, since the MR damper is a nonlinear device, the whole system is nonlinear.

The section is organized following the three steps described in Section 3. In the end, numerical and experimental outcomes will be compared in order to assess the feasibility of the model.

The measurements considered in this configuration are acceleration recorded by sensors a1-a8, relative displacement between structures at the second level, $\delta(t)$, the control force $u(t),\left(N_{m}=11\right)$, and the device voltage $V$.

When the adjacent structures are connected through the MR damper, the well-functioning of the entire control system must be previously checked. MR damper can operate between passive and semiactive mode at different voltage levels, reacting with a nonlinear control force when subjected to relative displacement. The signals measured to make the control algorithm work correctly are acquired by means of the acquisition board and then processed in a PC. A code implemented with LabView software applies the control law after interpreting the signals and then modulates the input voltage through the device actuator. The results obtained enabled confirming the validation of the passive and semiactive control system and of the entire control process. Considerations about the control aspects and the effectiveness of the control strategy can be found in [15]. In synthesis, the dynamic response of the structures can be noticeably reduced when an MR damper connects them at the top floor. Specifically, passive control reached very good performances in terms of response reduction, whereas, in comparison, semiactive control in some cases provided light additional improvements. This latter finding could be related to the adjacent structures, the type of structural configuration tested, that did not enhance the potentially more effective performances of semiactive control; but it was also due, in this specific case, to the device utilized in the experimental campaign, which seemed overestimated for the control system.

5.1. Vibration Analysis. The first test examined is the sine sweep at PGA $0.1 \mathrm{~g}$ with the MR damper working at $0 \mathrm{~V}$ (minimum voltage). Acceleration and control force time histories are shown in Figure 6(a). The first four frequencies observed, the same for both structures, are around 2.9, 7.9, 13.2, and $15.6 \mathrm{~Hz}$. As a first result, it should be noted that natural frequencies of the connected structures differ 


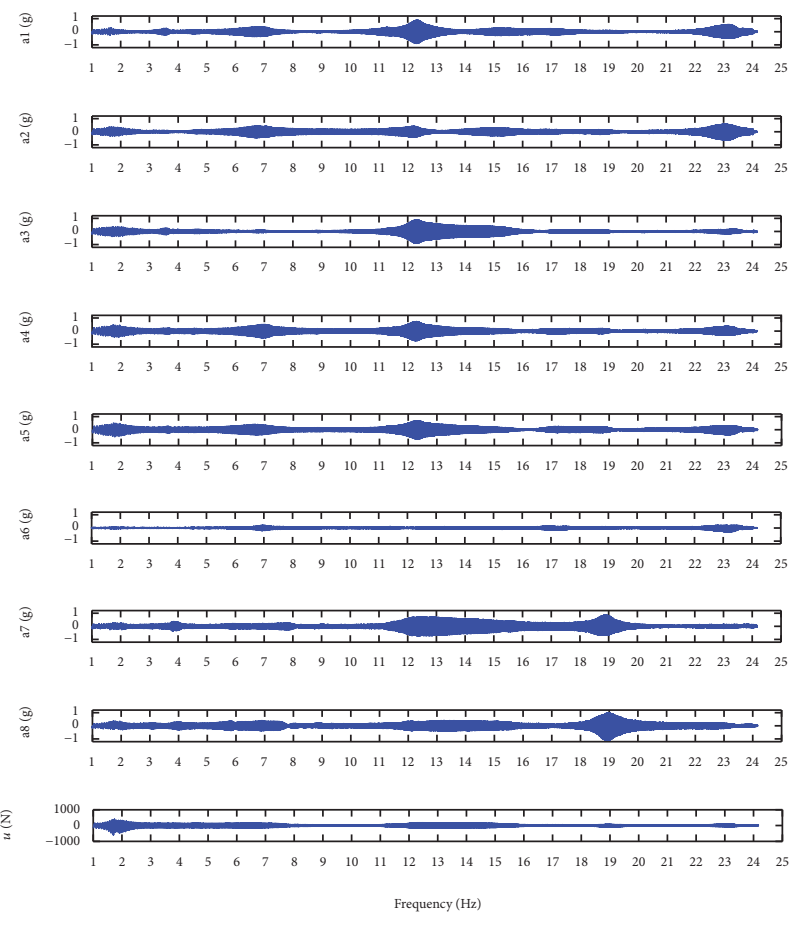

(a)

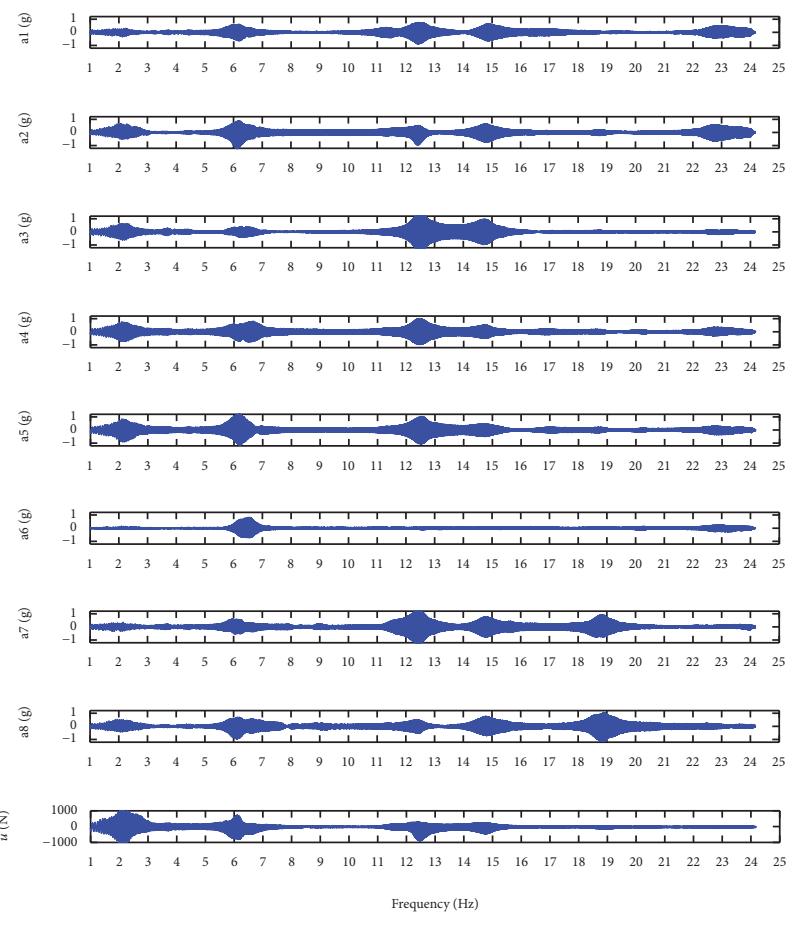

(b)

FiguRE 6: Passive connected (PC) configuration, acceleration measured by sensors al-a8 and control force, voltage level (a) $0 \mathrm{~V}$ and (b) $2.5 \mathrm{~V}$. Sine sweep frequency test PGA $0.1 \mathrm{~g}$.

from those detected in the NC configuration. In the passive configuration, first natural frequency of both structures is at about $2.9 \mathrm{~Hz}$, whereas in the NC configuration, the first frequencies of structure $\mathrm{A}$ and $\mathrm{B}$ were at about 2.54 and $5.10 \mathrm{~Hz}$, respectively. Concerning structure A, the first two frequencies are slightly influenced by the coupling, whereas the third and fourth ones are more influenced; besides, an amplification at the $24 \mathrm{~Hz}$ frequency is also observed. This frequency is not evident in the responses of structure $B$. Concerning structure $\mathrm{B}$, the coupling has strongly influenced its dynamics: the same four frequencies that were evident for structure A are noticed, none of them corresponding to those obtained in the NC case. An amplification at a frequency of around $19-20 \mathrm{~Hz}$, which was already observed in the NC configuration, is observed again for structure B. This frequency was not evident in the structure $\mathrm{A}$ responses (neither in the CC nor in the NC configuration). The results estimated with the FE model (Section 4.3) showed that such a frequency was probably associated with a torsional mode. It seems therefore that the control system, which acts only in the $x$ direction, does not influence this mode.

In general, the dynamic amplifications of both structures are less evident if compared with the NC configuration, Figure 4. Moreover, by observing the recorded control force time history $u(t)$, Figure 6(a), it can be noticed that its value is amplified for frequencies among 1 and $19 \mathrm{~Hz}$, and in this range the structures influence each other. For higher frequencies, the control force is lower and it does not modify the dynamics of structure B, while it is almost sufficient to activate the natural frequency at $24 \mathrm{~Hz}$ for structure A, which does not appear in structure B.

The acceleration and the control force time histories achieved for sine sweep base acceleration at PGA $0.1 \mathrm{~g}$ with MR damper working at $2.5 \mathrm{~V}$ (maximum voltage), are reported in Figure 6(b). Again, the coupling has modified the dynamics of the structures with respect to the NC configuration. The first two frequencies of the coupled structures changed from 2.9 to $3.2 \mathrm{~Hz}$ and from 7.9 to $7.2 \mathrm{~Hz}$, compared to the same test made with the MR damper working at $0 \mathrm{~V}$. The other resonance frequencies did not change and considerations similar to those concerning the case of $0 \mathrm{~V}$ may be done about the dynamics of the two structures. The control force time history $u(t)$ yields an amplification at frequencies which are common to both structures and shows higher values than in the case of $0 \mathrm{~V}$. Due to the greater value of the control force, the first two frequencies of the coupled structures were modified; the others remained equal since the increase of the control force was not influential.

Experimental results of the white noise test at $0.05 \mathrm{~g}$ with control device working at $2.5 \mathrm{~V}$ are also considered to better explain the dynamic behavior in the passive configuration. It was observed that, in such a configuration, the MR damper does not develop significant dissipation, due to the low bidirectional base excitation level, to the high values of the control force $u(t)$ and to the very low relative displacements $\delta(t)$. For this reason, the connection can be regarded as rigid and, in this context, the results can be analyzed in 


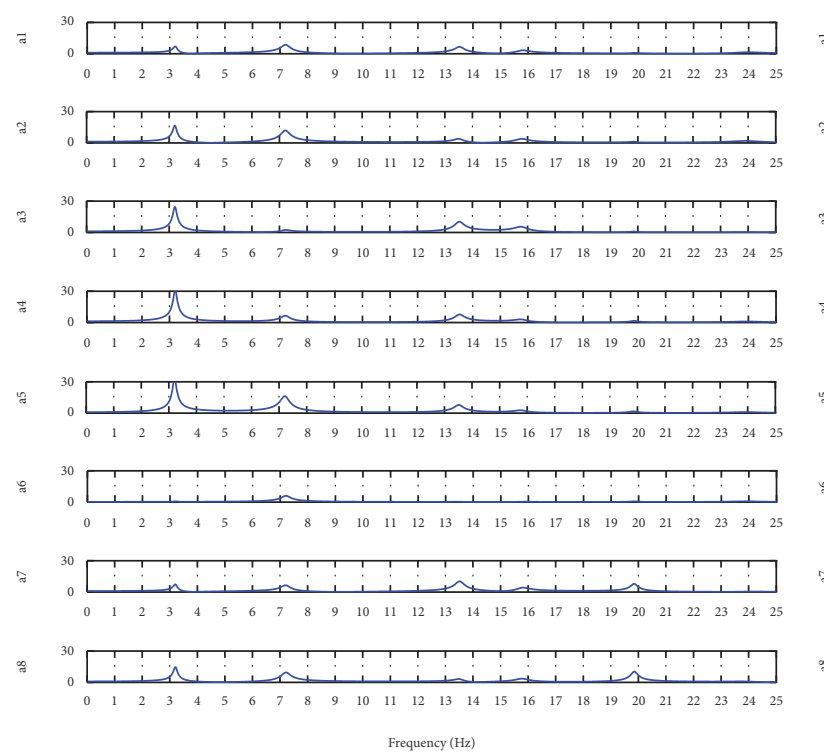

(a)

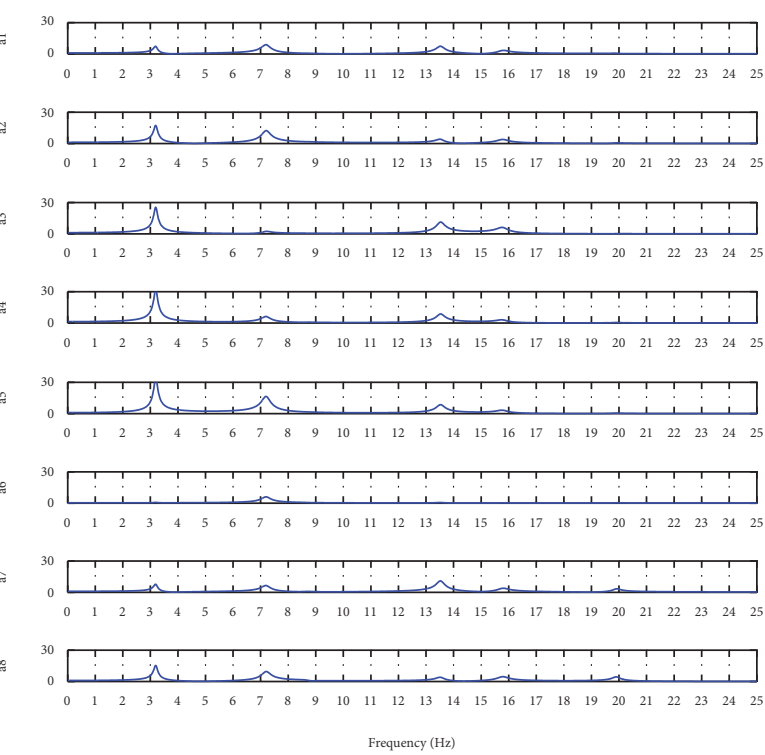

(b)

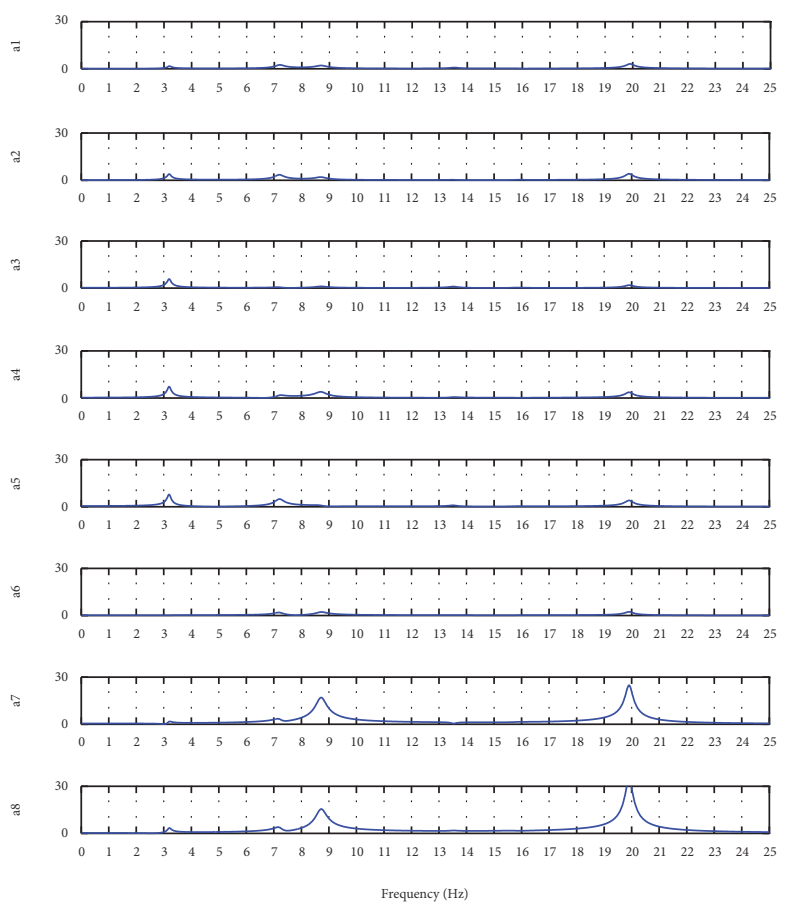

(c)

Figure 7: Rigid connected (RC) configuration, identified frequency response functions. Ground acceleration $x$ direction, (a) $H_{x} ; x-y$ directions, (b) $H_{x}$, and (c) $H_{y}$. White noise test PGA $0.05 \mathrm{~g}$.

the frequency domain through identified FRFs, $\mathbf{H}_{x}$ and $\mathbf{H}_{y}$, having assumed that the system is linearly elastic.

Figure 7 (a) shows the identified FRFs of sensors a1-a8, $\mathbf{H}_{x}$, when only ground acceleration in $x$ direction is considered. Five natural frequencies appear clearly for the rigidly connected (RC) system. For sensors a1-a5, located on structures $\mathrm{A}$ in $x$-direction, frequencies at around 3.2, 7.2, 13.5 and $16 \mathrm{~Hz}$ are evident; for sensor a6, located on structure $\mathrm{A}$ in $y$-direction, only a frequency at around $7.2 \mathrm{~Hz}$ is clear; for sensors a7-a8, on structure B in $x$-direction, the four frequencies reported for structure A are still clear, but also a resonant frequency at around $20 \mathrm{~Hz}$ shows up in this case.

Figures 7(b) and 7(c) show the identified FRFs $\mathbf{H}_{x}$ and $\mathbf{H}_{y}$ of sensors al-a8, respectively, considering both directions of the base excitation. It is worth noting that the $\mathbf{H}_{x}$ obtained considering the ground excitation in both directions, Figure 7(b), are very close to those achieved considering only the base excitation in the $x$ direction, Figure 7(a). FRFs in the $y$ direction for sensors a1-a6 on structure A, Figure 7(c), show the already highlighted frequencies at 3.2 and $7.2 \mathrm{~Hz}$, while 

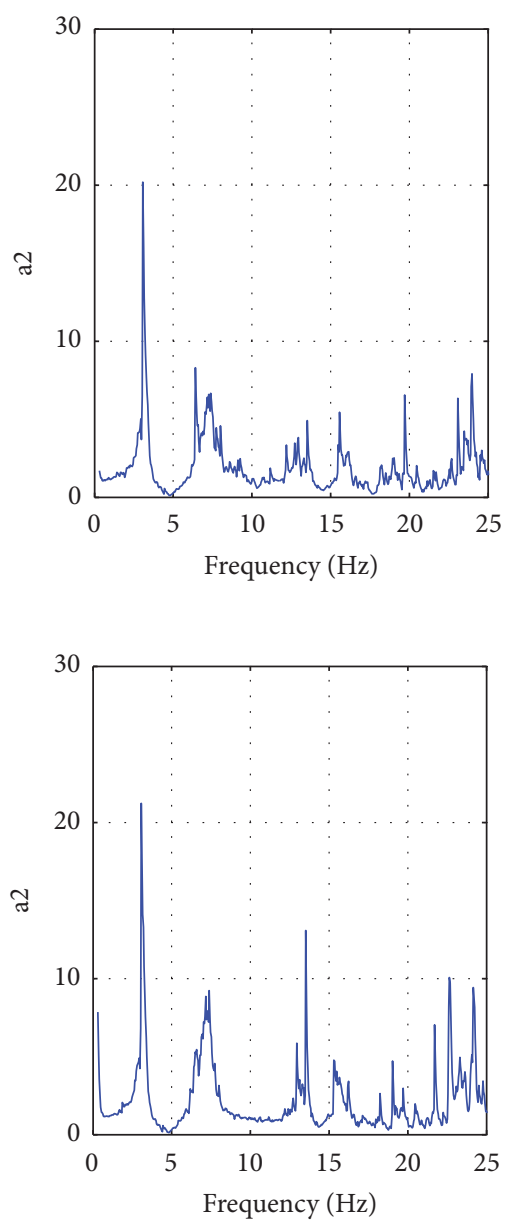

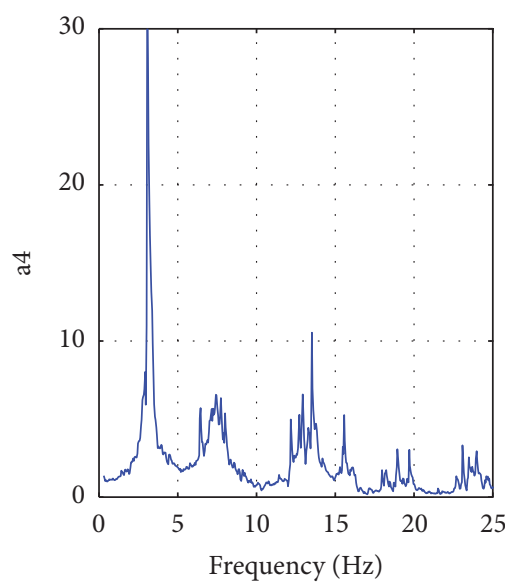

(a)

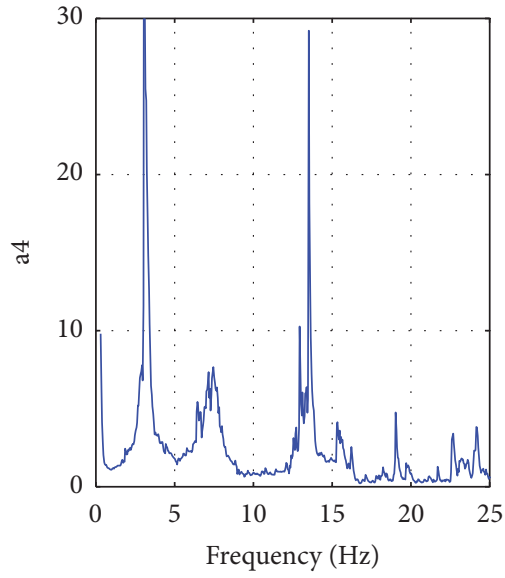

(b)
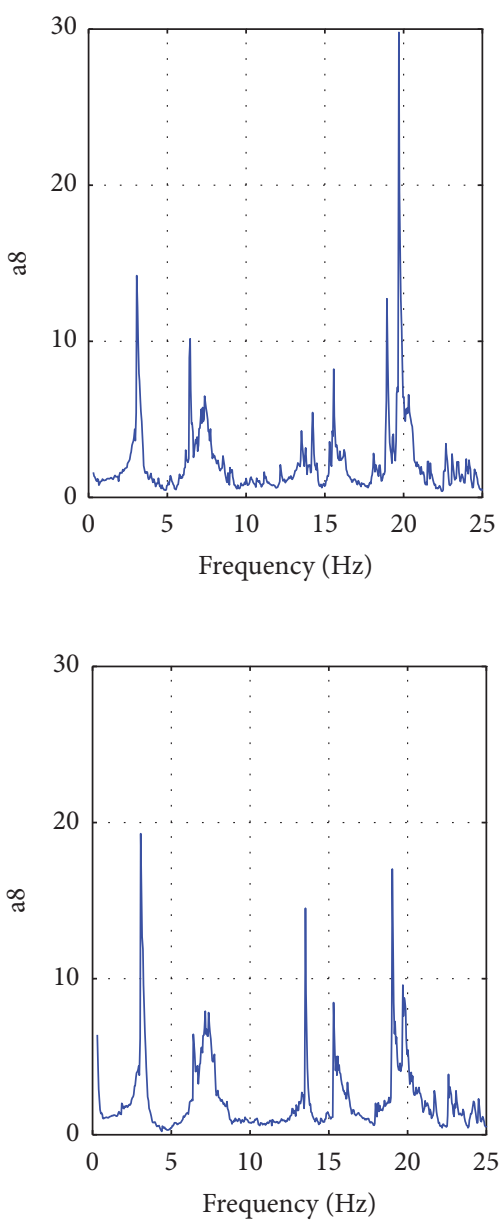

FIGURE 8: Passive connected (PC) configuration, experimental pseudo frequency response functions. Ground acceleration $x$ direction, voltage level (a) $1 \mathrm{~V}$ and (b) $2.5 \mathrm{~V}$. El Centro test PGA $0.6 \mathrm{~g}$.

also the frequency at around $20 \mathrm{~Hz}$ appears; for structure $\mathrm{B}$, with sensors a7-a8, frequencies at $3.2,7.2$, and $20 \mathrm{~Hz}$ are still evident, but also a resonant frequency at around $8.6 \mathrm{~Hz}$ can be observed. Besides, FRF relating to sensor a6 shows much lower amplitudes than other sensors' locations; only at around $7-8 \mathrm{~Hz}$ a small amplification is observed.

In case of natural earthquake input, the experimental response of the structures subjected to El Centro test at $0.6 \mathrm{~g}$ is reported. An elaboration of the acceleration responses in the frequency domain has been carried out also when the device operates in passive or semiactive mode. However, since in this case the controlled system behaves as nonlinear, pseudo frequency response functions (PFRFs) $\mathbf{H}_{x}$ are estimated, defined as the ratio between the Fourier transform of the acceleration and the Fourier transform of the seismic input. Figures $8(\mathrm{a})$ and $8(\mathrm{~b})$ show the experimental PFRFs relative to sensors a2 and a4 for structure A and to sensor a8 for structure $\mathrm{B}$ in passive mode at 1 and $2.5 \mathrm{~V}$ respectively. Figures 9(a) and 9(b) show instead the same experimental PFRFs in semiactive mode at $0-1$ and $0-2.5 \mathrm{~V}$, respectively. By observing such signals, it is clearly noticed that peculiarly, once the system is controlled, despite its nonlinearity, the same vibrational frequencies emerge regardless of the device mode and the voltage level. Surely, the system dynamics changes by changing the amplifications but the natural frequencies remain the same. Thus, system natural frequencies observed in the passive or semiactive mode can be found among the frequencies observed in the NC and RC cases, which represent two limit situations.

Figure 10 compares, for structure A's sensor a4 and for structure B's sensor a8, experimental FRF in the NC and RC cases with experimental PFRFs relating to PC at 0,1 , and $2 \mathrm{~V}$, in case of white noise input $0.1 \mathrm{~g}$. The figure outlines some aspects which have been separately observed in other figures. It is clearly observed the resonance frequencies shift from the NC case to the connected cases (RC and PC). Moreover, when the structures are linked, the same frequencies are observed for both. It is also interesting to notice that FRF in NC case, FRF in RC case, and PFRFs in passive cases intersect in the same fixed points. Regarding the amplifications, the effectiveness of the control system emerges: for structure A the first amplification is strongly attenuated with passive 

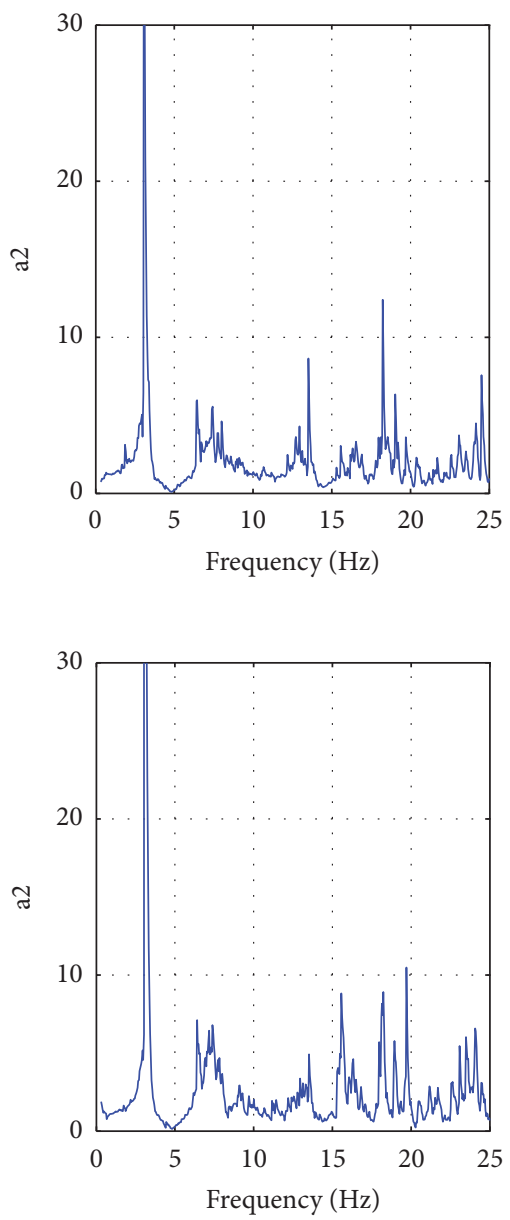

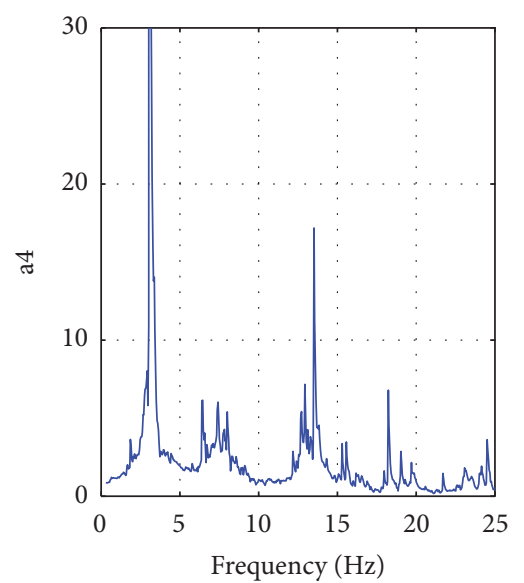

(a)

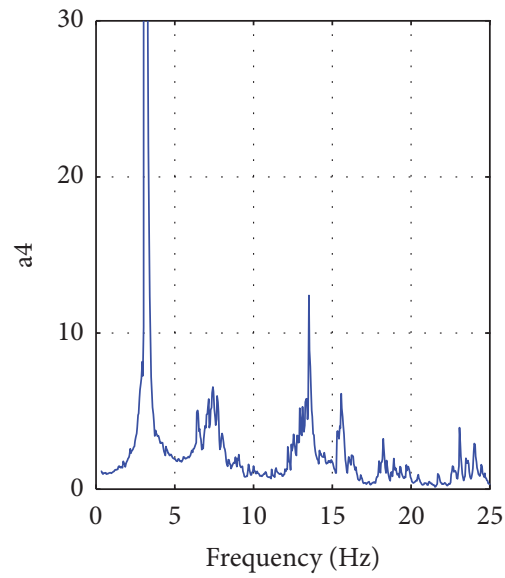

(b)
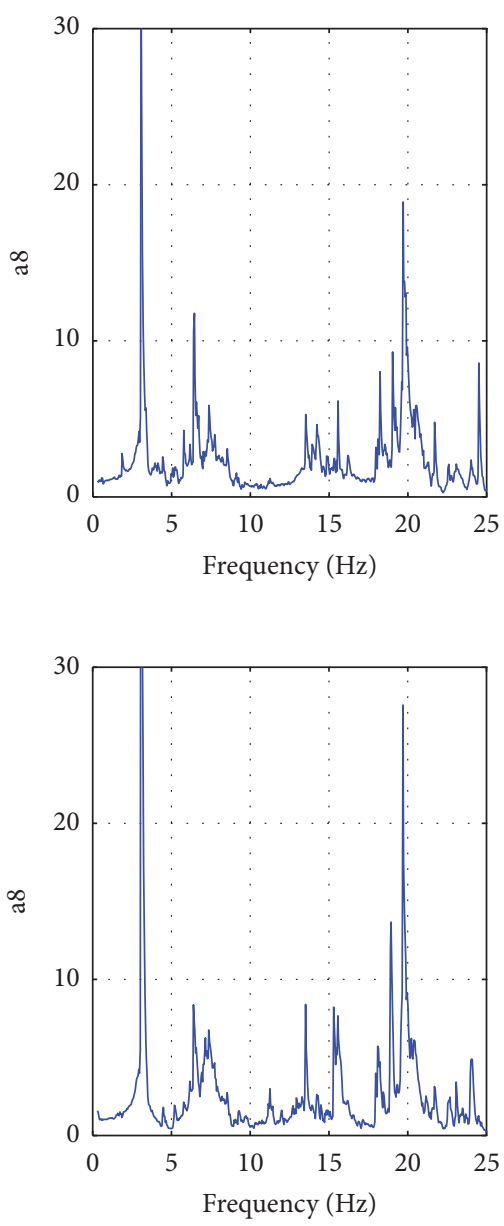

FIGURE 9: Semiactive connected (SAC) configuration, experimental pseudo frequency response functions. Ground acceleration $x$ direction, voltage level (a) 0-1 V and (b) 0-2.5 V. El Centro test PGA $0.6 \mathrm{~g}$.

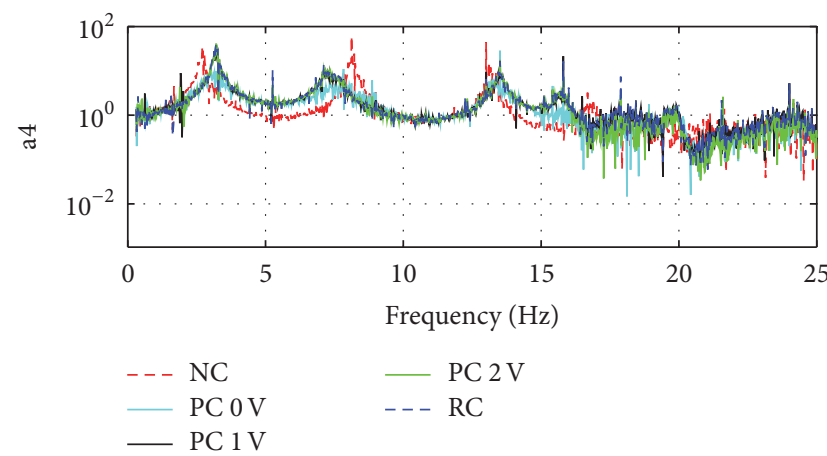

(a)

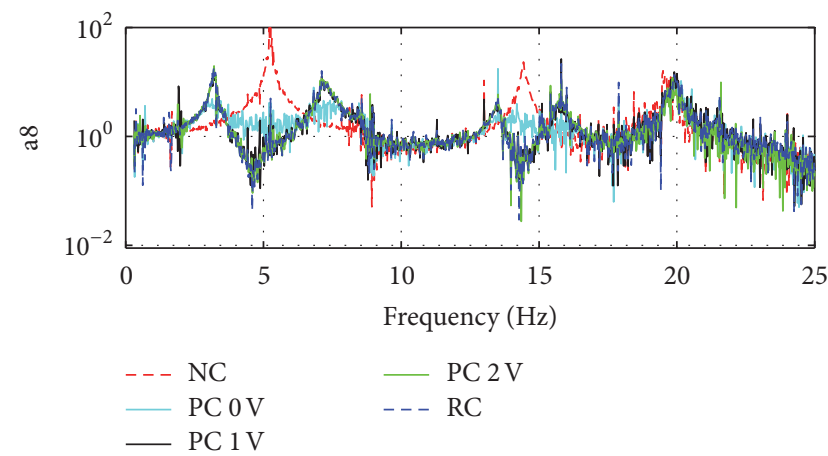

(b)

FIGURE 10: Experimental frequency response functions. Ground acceleration $x$ direction nonconnected (NC), rigid connected (RC), and passive connected (PC) 0,1 and $2 \mathrm{~V}$ configurations, (a) sensor a4 and (b) sensor a8. White noise test PGA 0.1 g.

connection at $0 \mathrm{~V}$, and also the others are evidently reduced; for structure $\mathrm{B}$ all the amplifications are reduced in the RC case and in all PC cases.

By comparing experimental FRF related to $\mathrm{NC}$ and $\mathrm{RC}$ cases and experimental PFRFs related to semiactive cases, similar results (not reported for the sake of brevity) are obtained.

Similar aspects are confirmed also by observing responses time histories and other earthquake inputs; the results are therefore not reported for the sake of brevity. 
TABLE 11: Identified natural frequencies and damping ratios in the nonconnected (NC) and rigid connected (RC) configuration; white noise test PGA $0.1 \mathrm{~g}$.

\begin{tabular}{|c|c|c|c|c|c|c|}
\hline \multirow{2}{*}{ Mode } & \multicolumn{2}{|c|}{ Structure A (NC) } & \multicolumn{2}{|c|}{ Structure B (NC) } & \multicolumn{2}{|c|}{ Connected structure (RC) } \\
\hline & Frequency $(\mathrm{Hz})$ & Damping (\%) & Frequency $(\mathrm{Hz})$ & Damping (\%) & Frequency $(\mathrm{Hz})$ & Damping (\%) \\
\hline 1 & 2.70 & 2.29 & 5.25 & 0.75 & 3.18 & 2.35 \\
\hline 2 & 8.15 & 1.05 & 14.43 & 0.53 & 7.26 & 2.45 \\
\hline 3 & 13.18 & 0.98 & 19.66 & 0.41 & 8.63 & 1.91 \\
\hline 4 & 16.85 & 1.12 & & & 13.53 & 1.11 \\
\hline 5 & & & & & 15.78 & 1.19 \\
\hline 6 & & & & & 19.94 & 0.69 \\
\hline 7 & & & & & 23.70 & 2.52 \\
\hline
\end{tabular}

As a matter of fact, the modification of dynamic behavior depends on seismic action type, on the PGA value, and on the intensity of the control force (i.e., voltage level).

\subsection{Identification of the First-Order Model in RC Configura-} tion. In order to obtain modal and physical system parameters in the connected case, the identification procedure described has been utilized and applied with reference to the case in which the connection can be regarded as rigid. The identified first-order modal models in terms of frequencies, damping ratios, and seismic eigenvectors are obtained.

Table 11 reports the identified natural frequencies and damping ratios relative to the white noise test with PGA $0.1 \mathrm{~g}$. By comparing the identified frequencies with those observed through the experimental FRFs in the white noise test at $0.05 \mathrm{~g}$ (see Figure 7 ), it can be noticed that the identification procedure well defines both the frequencies related to motion in $x$ direction (first, second, fourth, and fifth frequencies) and those in $y$ (third frequency) direction, also in the case of rigid connection. Moreover, the identification procedure brings out two additional frequencies (sixth and seventh) which were not observed in the vibration analysis (Section 5.1). Identified damping factors attain a maximum value of $2.45 \%$ at the second mode and a minimum value of $0.69 \%$ at the sixth mode.

The identified frequencies obtained in the $\mathrm{RC}$ configuration are then compared with the ones obtained in the NC configuration with the same input and PGA. It is confirmed what was observed in the vibration analysis: the rigid connection modifies the dynamic response of the system. The first frequency of the coupled structures is higher than structure A's uncoupled frequency and lower than the uncoupled one of structure B. The other frequencies, instead, are all lower than the corresponding ones for the uncoupled structures. It is interesting to underline that resonance frequencies obtained with the rigid connection are very close to the ones observed in passive and semiactive cases. Instead, damping ratios in the $\mathrm{RC}$ configuration are generally greater than the corresponding ones for the two unconnected structures, especially with reference to structure B.

Figures 11(a) and 11(b) show the identified seismic eigenvectors, sensors a1-a4 for structure A and a7-a8 for structure $\mathrm{B}$, for $\mathrm{NC}$ and RC configuration, respectively, for the white noise test with PGA $0.1 \mathrm{~g}$. In the RC configuration, the 1st, 2nd, 4th, and 5th frequencies are reported for structure $A$ and the 1st and 2nd ones are given for structure B. In the $\mathrm{NC}$ configuration, the first four frequencies are reported for structure A and the first two for structure B. It is clear that the shapes and amplitudes relating to the 1st, 2nd, 4th, and 5 th modes for structure A in the RC configuration are similar to those of the NC configuration, whereas, for structure B, only the first mode shape is similar for both configurations, though it shows lower amplitudes for the RC configuration.

5.3. FE Model and Updating Procedure: Numerical-Experimental Comparison. The numerical model of the adjacent structures linked by the MR damper is here defined. The FE model developed in Section 4.3 is adopted for the two structures, whereas the numerical model described in (7) and (8) is adopted for the MR damper. Cases assuming both a rigid and a passive/semiactive connection are considered. The initial values assumed for the MR damper model are based on a previous experiment conducted by the authors, which involved characterization tests of the device alone through sinusoidal displacement input at different frequencies and amplitudes [35]. The following fixed values are assumed: the linear spring, $K_{0}=2640 \mathrm{~N} / \mathrm{m}$, the yielding displacement, $\delta_{y}=10^{-5} \mathrm{~m}$, and the parameters that influence the shape of the force-displacement cycle $\bar{A}=1, \bar{\alpha}=\bar{\gamma}=0.5$, and $n=1$ [35]. $F_{y}$ and $C_{0}$ are the parameters depending on the input voltage.

In order to obtain a rigid connection, $F_{y}$ and $C_{0}$ are assumed to be sufficiently high, whereas in order to obtain a passive or semiactive connection, $F_{y}$ and $C_{0}$ are varied as follows:

$$
\begin{aligned}
& C_{0}=1000(0.44 V+0.51)[\mathrm{KNs} / \mathrm{m}] \\
& F_{y}=277 V[\mathrm{kN}]
\end{aligned}
$$

where $V$ is the input voltage in $\mathrm{V}$.

At first, the FE model with the rigid connection is discussed. The natural frequencies and excited masses percentages of the FE model in the rigid connection configuration are reported in Table 12. By comparing the numerical and experimentally identified frequencies, a very good correspondence is noticed. The model shows that the significant modes in $x$ direction are the first, the second, the sixth, and the seventh. Such modes coincide with those experimentally identified and reported in Table 11 as modes 1, 2, 4, and 5. The numerical mode at the frequency $8.48 \mathrm{~Hz}$ is a translational 
TABLE 12: Rigid connected (RC) configuration FE model natural frequencies and excited masses.

\begin{tabular}{|c|c|c|c|c|c|c|c|c|c|c|c|c|c|c|c|c|c|}
\hline Mode & 1 & 2 & 3 & 4 & 5 & 6 & 7 & 8 & 9 & 10 & 11 & 12 & 13 & 14 & 15 & 16 & 17 \\
\hline Frequency $(\mathrm{Hz})$ & 3.19 & 7.25 & 8.48 & 9.33 & 11.40 & 13.54 & 15.86 & 16.46 & 22.08 & 32.29 & 32.94 & 47.35 & 58.37 & 62.10 & 64.98 & 74.44 & 80.03 \\
\hline$\% X$ & 85.08 & 12.65 & 0.00 & 0.00 & 0.01 & 1.20 & 0.26 & 0.00 & 0.00 & 0.00 & 0.00 & 0.00 & 0.00 & 0.00 & 0.00 & 0.00 & 0.00 \\
\hline$\% Y$ & 0.01 & 0.03 & 51.18 & 0.00 & 0.00 & 0.01 & 0.00 & 0.00 & 29.49 & 0.00 & 13.50 & 0.00 & 0.00 & 2.02 & 3.44 & 0.00 & 0.33 \\
\hline$\%$ Rot & 0.00 & 0.00 & 0.00 & 43.58 & 0.00 & 0.00 & 0.00 & 41.06 & 0.00 & 9.35 & 0.00 & 4.28 & 1.53 & 0.00 & 0.00 & 0.22 & 0.00 \\
\hline
\end{tabular}

Structure A

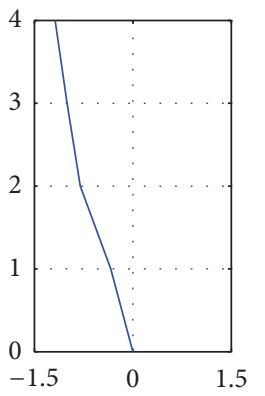

- 1 st

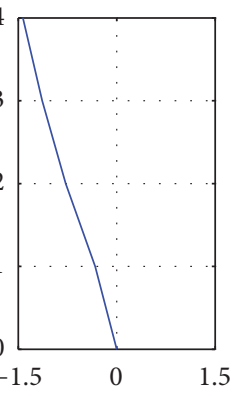

-1 st

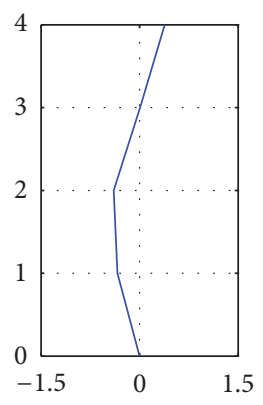

- 2nd
Structure A

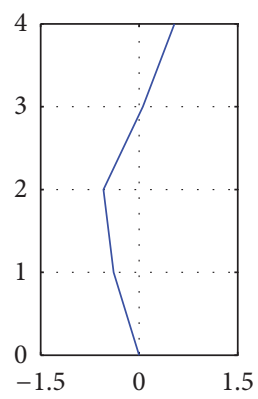

- 2nd

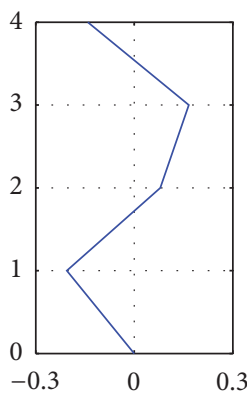

- 3rd

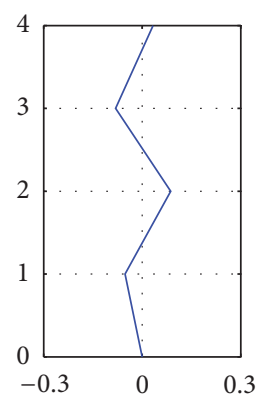

- 4th

(a)

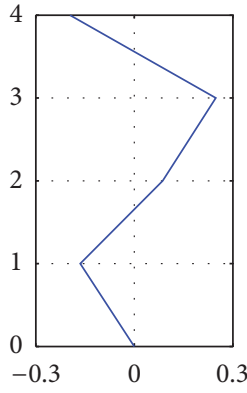

- 4th

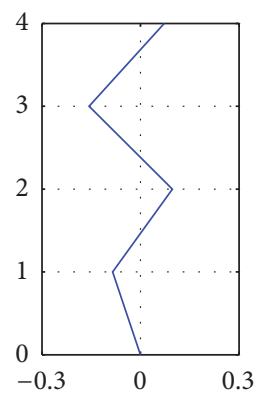

- 5 th

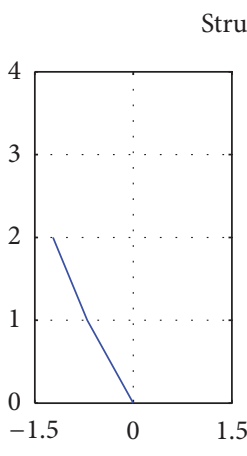

- 1 st
Structure B

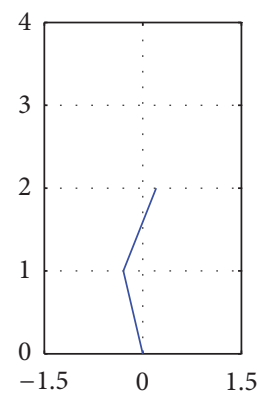

- 2nd

Structure B

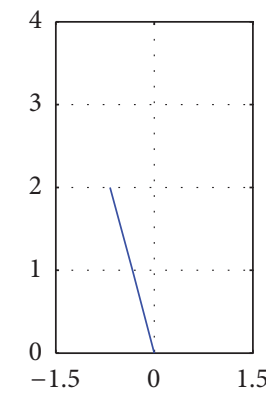

-1 st

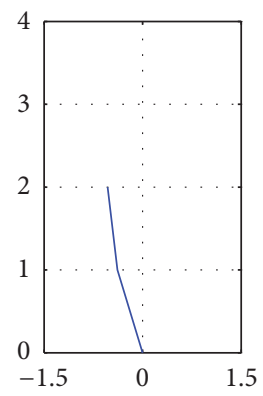

- 2nd

(b)

FIGURE 11: Identified seismic eigenvectors: (a) nonconnected (NC) and (b) rigid connected (RC) configuration. White noise test PGA 0.05 g.

mode in $y$ direction; it corresponds to the one identified as mode 3 in Table 11. Instead, the last two identified modes of Table 11 (mode 6 and 7) are not related to any of the modes shown in the numerical FE model. The comparison between the numerical and the experimentally identified seismic eigenvectors, here not reported for the sake of brevity, showed a good correspondence, with errors having the same order of magnitude obtained in the NC case. Thus, the identification procedure was valid and the numerical model was applicable both in the $\mathrm{NC}$ and in the $\mathrm{RC}$ configuration.

In passive or semiactive mode, the numerical FE model having the same parameters assumed in (12a) and (12b) for the MR damper did not reproduce the experimental results in an acceptable way. The discrepancies observed can be ascribed to the fact that the MR damper characterization described in [35] was carried out in a different range of displacement and frequencies. In fact, in [35] applied displacement $\delta$ and frequency $\Omega$ were lower $( \pm 1 \mathrm{~mm}$ $<\delta< \pm 5 \mathrm{~mm}, 1 \mathrm{~Hz}<\Omega<5 \mathrm{~Hz}$ ) than the values involved in this experimental campaign. Only the first natural frequency of the structures can be compared to the range of frequencies investigated in [35], while all the others are much higher; moreover, displacements recorded between the structures can reach $20 \mathrm{~mm}$. Those differences have considerably affected the $C_{0}$ parameter, the only one considered as depending on the values of $\delta$ and $\Omega$. For this reason, an optimization procedure was applied to update $C_{0}$ on the FE model, starting from the values obtained by (12a).

In the optimization procedure, time histories and maximum-minimum responses are collected in the following vectors:

$$
\begin{aligned}
\mathbf{g}(t) & =\left[\begin{array}{llll}
\mathbf{u}^{T}(t) & \boldsymbol{\delta}^{T}(t) & \mathbf{x}^{T}(t) & \mathbf{a}^{T}(t)
\end{array}\right]^{T} ; \\
\mathbf{G} & =\left[\begin{array}{llll}
u^{\max } & u^{\min } & \delta^{\max } & \delta^{\min }
\end{array}\right]^{T},
\end{aligned}
$$




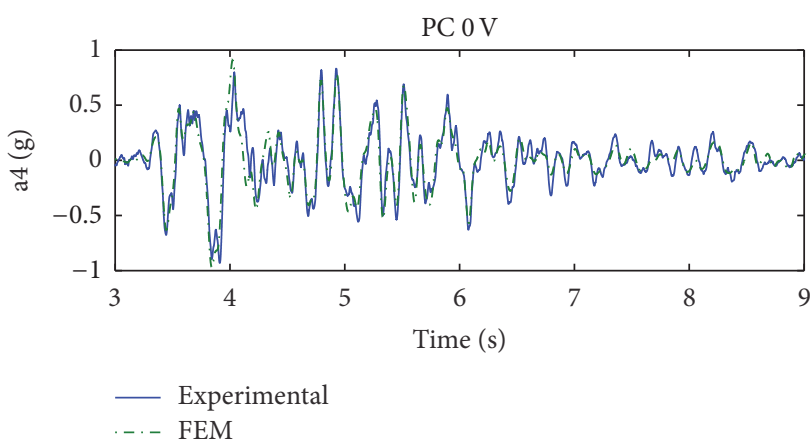

(a)

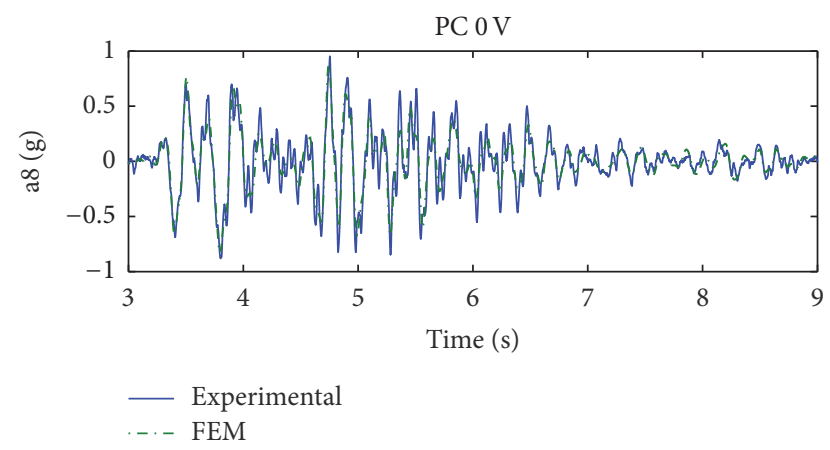

(b)

FIGURE 12: Passive connected configuration (PC), experimental versus FEM 4th floor structure A and 2nd floor structure B acceleration $x$ direction, voltage level $0 \mathrm{~V}$. Kobe test PGA $0.5 \mathrm{~g}$.

where $\mathbf{u}(t), \boldsymbol{\delta}(t), \mathbf{x}(t)$, and $\mathbf{a}(t)$ are the MR force and deformation, the displacement and the absolute acceleration of structures, respectively; $u^{\max }, u^{\min }, \delta^{\max }$ and $\delta^{\min }$ are the maximum and minimum MR force and deformation.

The error functions between the measured and the calculated values (overlined quantities) are defined as follows:

$$
\begin{aligned}
\mathbf{e}(p, t) & =\mathbf{g}(t)-\overline{\mathbf{g}}(p, t) ; \\
\mathbf{E}(p) & =\mathbf{G}(p)-\overline{\mathbf{G}}(p)
\end{aligned}
$$

in which $p=\left[C_{0}\right]$.

The diagonal terms of weighting matrix for the time history and the maximum and minimum responses are defined as follows:

$$
\begin{aligned}
w_{i} & =\frac{q_{i}}{\max \left(\mathbf{g}_{i}(t)\right)} ; \\
W_{j} & =\frac{Q_{j}}{G_{j}} .
\end{aligned}
$$

For the time histories and the maximum and minimum responses, (13), the following values are used: $q_{i}=$ $10,100,100,1 ; Q_{j}=10,10,100,100$.

The value of $p$ is carried out by minimizing the weighted penalty function:

$$
\mathbf{J}=\frac{1}{2} \mathbf{e}(p, t)^{T} \mathbf{w e}(p, t)^{T}+\frac{1}{2} \mathbf{E}(p, t)^{T} \mathbf{W E}(p, t)^{T} .
$$

The values obtained for the updated parameter $C_{0}$ range from 3.5 to 7.5 times the starting value of the parameter obtained with (12a). It is important to underline that the number of iterations used in the optimization procedure was very low: that is, less than 10 iteration were sufficient to lead to the updated value.

Figures 12 and 13 show results obtained for the Kobe test at $0.5 \mathrm{~g}$ and the device working at $0 \mathrm{~V}$. The acceleration in the $x$ direction, calculated through the FE model, well reproduces the corresponding experimental values (Figure 12 structure A's 4th floor and structure B's 2nd floor acceleration). Also the MR device's force-displacement cycles, shown in Figure 13, well-fit the experimental behavior. The main aspects of the structural response are well reproduced. Similar results are obtained comparing numerical and experimental results for the MR damper working at other input voltages.

Finally, the FE model is utilized to reproduce the experimental data in semiactive modality. The MR device works between two input voltages, in accordance with an ON-OFF control law; as an example, here the case $0-1.5 \mathrm{~V}$ is reported. The model reproduces the experimental acceleration for both structures in a quite precise way, Figure 14. Moreover, also the MR device's force-displacement cycle appears well reproduced, Figure 15.

5.4. From $3 D$ to $2 D$ Numerical Model. Even if the system showed a substantially planar behavior, so far, a threedimensional model was adopted. In fact, the asymmetry of the physical model and the light degree of coupling highlighted for some modes were considered. Nevertheless, by analyzing the recorded base acceleration, sensors $G_{x}$ and $G_{y}$ in Figure 4, it has been observed that the acceleration in $y$ direction has an average maximum value equal to $20 \%$ of the acceleration in the $x$ direction. Therefore, the base excitation is almost completely contained in the $x z$ plan.

Experimental data and the identified modal and physical parameters suggested that structural responses in the $x$ direction are almost exclusively related to the base excitation in the same direction. Consequently, a two-dimensional (2D) model can be derived from the 3D numerical one. To do that, it is sufficient to consider only the translational DOFs in $x$ direction for structures A and B, erasing from the stiffness matrices (Tables 7 and 8) and from the mass matrices all the values related to the other DOFs.

\section{Conclusions}

The paper illustrated the vibration analysis of adjacent structures controlled by a MR damper and the discussion of a numerical procedure for identification and definition of a reliable finite element model. The tridimensional physical model consisted of a four-story structure and a two-story structure connected at the second level by the control device with the possibility of acting in passive or in semiactive mode. 

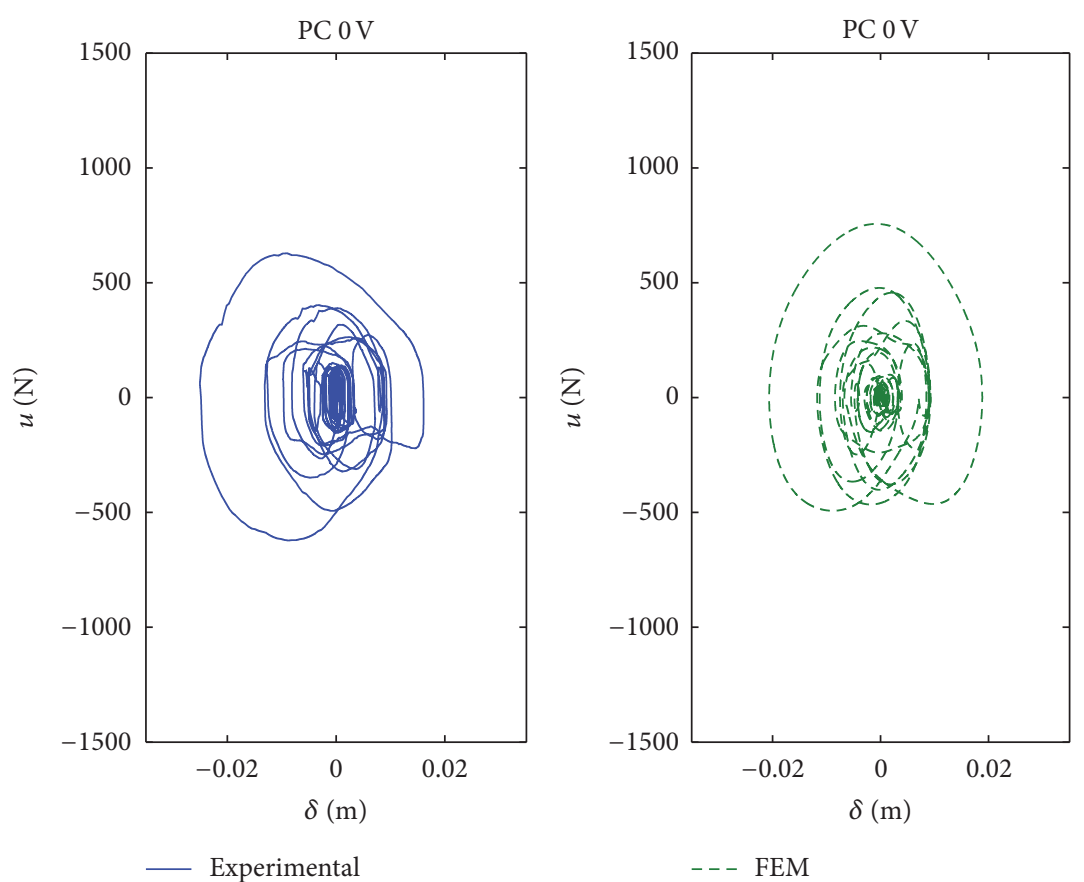

FIGURE 13: Passive connected (PC) configuration, experimental versus FEM force-displacement, loop voltage level 0 V. Kobe test PGA 0.5 g.

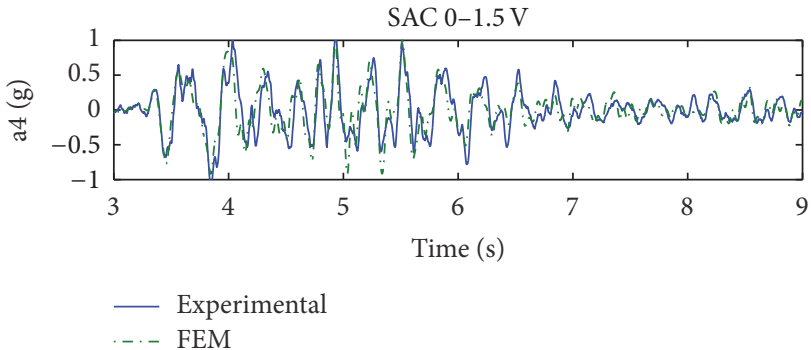

(a)

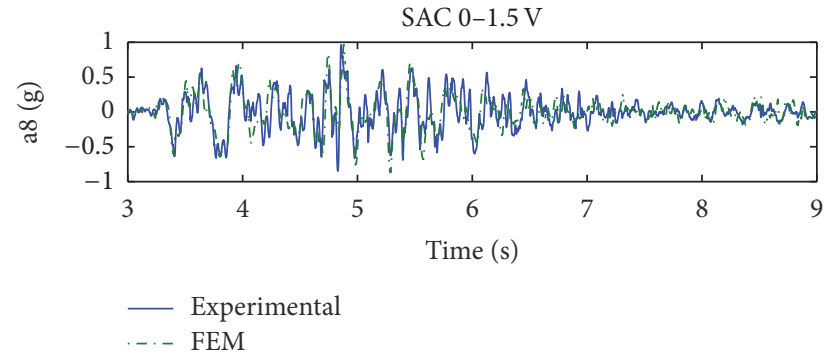

(b)

FIgURE 14: Semiactive connected (SAC) configuration, 0-1.5 V, experimental versus FEM 4th floor structure A and 2nd floor structure B acceleration $x$ direction. Kobe test PGA $0.5 \mathrm{~g}$.

On the one hand, the results of an extensive experimental campaign carried out using shaking table tests, devoted to investigate the dynamic behavior of the uncoupled and coupled structures utilizing a wide variety of base excitations at several intensities, have been presented. On the other hand, a procedure for the structural identification and the definition of a reliable numerical model for adjacent structures connected by an MR damper making use of experimental results has been illustrated. Specific conclusions of the study in the nonconnected and connected configuration are summarized as follows.

6.1. Nonconnected Configuration. The vibration analysis detected a different dynamic behavior between the two frames. Four natural frequencies for structure A and three for structure B were observed. Frequencies, damping ratios, and seismic eigenvectors of the first-order modal model were identified at different PGA levels. The light shifts observed in the values of the frequencies and damping ratios suggested a modest nonlinear structural behavior. An accurate 3D FE model of the two uncoupled structures has been obtained; by comparing experimental and numerical data, the achievement of a good agreement in both the time and frequencies domains was observed.

6.2. Connected Configuration. The vibration analysis detected that the connection modified the dynamic structural behavior compared to the nonconnected configuration in a wide range of frequencies. For both structures, the fundamental frequencies were shifted and the observed vibratory modes were almost the same. The connected configuration with the device working at $2.5 \mathrm{~V}$ can be regarded in some cases as a rigid connection. In this situation, the system has been considered to behave linearly and the dynamic characteristics were studied considering experimental frequency response functions. The structures identification with rigid connection gave frequencies, damping ratios, and seismic eigenvectors. The dynamic characteristics of the FE model of the two 

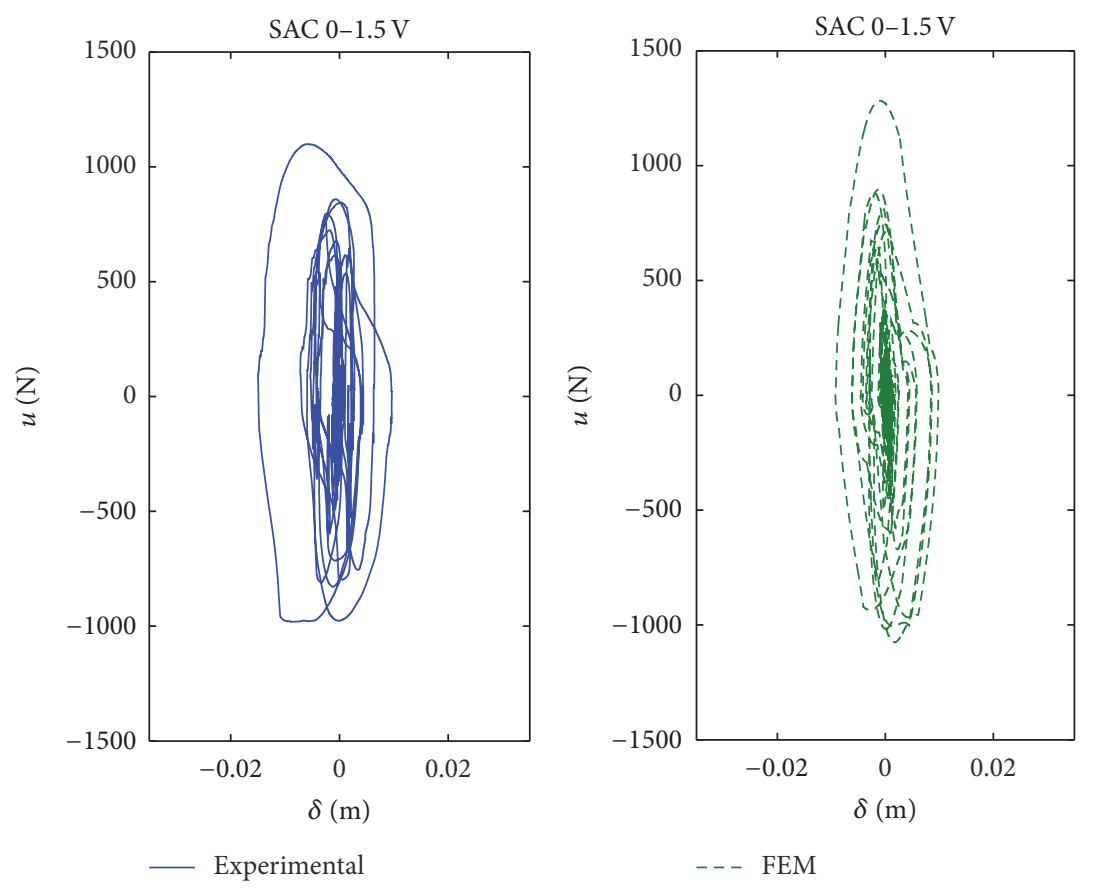

FIGURE 15: Semiactive connected (SAC) configuration, 0-1.5 V, experimental versus FEM force-displacement loop. Kobe test PGA 0.5 g.

structures with a rigid connection were compared with the identified ones observing a very good accordance. When the device operated in passive and semiactive mode, it emerged that the dynamics of the system only changed in terms of dynamic amplifications, but the resonance frequencies remained unchanged, situated among the frequencies observed in the $\mathrm{NC}$ and $\mathrm{RC}$ cases.

A modified Bouc-Wen element was chosen to model the MR damper and the parameters were updated to reproduce the experimental outcomes. The coupled FE model was determined putting the updated MR damper model together with the one previously defined for the uncoupled structures. The complete FE model was capable of efficiently reproducing the dynamics of the adjacent structures rigidly, passively, or semiactively connected, by adequately setting the MR device parameters.

As a conclusion, when dealing with the characterization of structures equipped with control devices, the results of this paper confirm the possibility of considering, in a first stage, the uncoupled structures and then defining an updated FE model. In a second stage, a suitable model for the control device can be considered; in the end, a fine-tuning with the experimental response of the mechanical parameters can be made and it should be assembled with the model defined for the uncoupled structures.

The knowledge of modal characteristics and the availability of an updated model are fundamental matters for a structural monitoring program that could reveal any gradual decay due to aging in the integrity of the structures.

\section{Competing Interests}

The authors declare that they have no competing interests.

\section{Acknowledgments}

The authors gratefully thank Dr. Giancarlo Fraraccio for the contribution he has made supporting this research work with numerical studies.

\section{References}

[1] G. W. Housner, L. A. Bergman, T. K. Caughey et al., "Structural control: past, present, and future," Journal of Engineering Mechanics, vol. 123, no. 9, pp. 897-971, 1997.

[2] H. P. Zhu, D. D. Ge, and X. Huang, "Optimum connecting dampers to reduce the seismic responses of parallel structures," Journal of Sound and Vibration, vol. 330, no. 9, pp. 1931-1949, 2011.

[3] A. V. Bhaskararao and R. S. Jangid, "Seismic analysis of structures connected with friction dampers," Engineering Structures, vol. 28, no. 5, pp. 690-703, 2006.

[4] M. De Angelis and V. Ciampi, "Effectiveness of dissipative connections on improving the earthquake response of adjacent structures," in Proceedings of the 10th European Conference on Earthquake Engineering, pp. 1891-1986, Balkema, Rotterdam, The Netherlands, 1994.

[5] Y. Q. Ni, J. M. Ko, and Z. G. Ying, "Random seismic response analysis of adjacent buildings coupled with non-linear hysteretic dampers," Journal of Sound and Vibration, vol. 246, no. 3, pp. 403-417, 2001.

[6] M. Basili and M. De Angelis, "A reduced order model for optimal design of 2-mdof adjacent structures connected by hysteretic dampers," Journal of Sound and Vibration, vol. 306, no. 1-2, pp. 297-317, 2007.

[7] M. Basili and M. De Angelis, "Optimal passive control of adjacent structures interconnected with nonlinear hysteretic devices," Journal of Sound and Vibration, vol. 301, no. 1-2, pp. 106-125, 2007. 
[8] F. Palacios-Quiñonero, J. Rubió-Massegú, J. M. Rossell, and H. R. Karimi, "Semiactive-passive structural vibration control strategy for adjacent structures under seismic excitation," Journal of the Franklin Institute, vol. 349, no. 10, pp. 3003-3026, 2012.

[9] S. D. Bharti, S. M. Dumne, and M. K. Shrimali, "Seismic response analysis of adjacent buildings connected with MR dampers," Engineering Structures, vol. 32, no. 8, pp. 2122-2133, 2010.

[10] R. E. Christenson, B. F. Spencer, and E. A. Johnson, "Semiactive connected control method for adjacent multidegree-offreedom buildings," Journal of Engineering Mechanics, vol. 133, no. 3, pp. 290-298, 2007.

[11] Y. L. Xu, S. Zhan, J. M. Ko, and W. S. Zhang, "Experimental investigation of adjacent buildings connected by fluid damper," Earthquake Engineering and Structural Dynamics, vol. 28, no. 6, pp. 609-631, 1999.

[12] Z. Yang, Y. L. Xu, and X. L. Lu, "Experimental seismic study of adjacent buildings with fluid dampers," Journal of Structural Engineering, vol. 129, no. 2, pp. 197-205, 2003.

[13] G. Fraraccio and M. De Angelis, "Strutture adiacenti controllate mediante dispositivi elastoplastici in acciaio," Ingegneria Sismica, vol. 2, pp. 5-16, 2006 (Italian).

[14] K. Makita, R. E. Christenson, K. Seto, and T. Watanabe, "Optimal design strategy of connected control method for two dynamically similar structures," Journal of Engineering Mechanics, vol. 133, no. 12, pp. 1247-1257, 2007.

[15] M. Basili, M. De Angelis, and G. Fraraccio, "Shaking table experimentation on adjacent structures controlled by passive and semi-active MR dampers," Journal of Sound and Vibration, vol. 332, no. 13, pp. 3113-3133, 2013.

[16] H. Iemura, A. Igarashi, and N. Nakita, "Full-scale verification tests of semiactive control of structures using variable joint damper system," in Proceedings of the 3rd World Conference on Structural Control, Como, Italy, 2003.

[17] R. E. Christenson, J. Spencer, N. Hori, and K. Seto, "Coupled building control using acceleration feedback," Computer-Aided Civil and Infrastructure Engineering, vol. 18, no. 1, pp. 4-18, 2003.

[18] Y. L. Xu, J. Chen, C. L. Ng, and W. L. Qu, "Semiactive seismic response control of buildings with podium structure," Journal of Structural Engineering, vol. 131, no. 6, pp. 890-899, 2005.

[19] C.-H. Loh, J.-H. Weng, C.-H. Chen, and K.-C. Lu, "System identification of mid-story isolation building using both ambient and earthquake response data," Structural Control and Health Monitoring, vol. 20, no. 2, pp. 139-155, 2013.

[20] F. Ikhouane and J. Rodellar, Systems with Hysteresis: Analysis, Identification and Control Using the Bouc-Wen Model, John Wiley \& Sons, 2007.

[21] N. D. Oliveto, G. Scalia, and G. Oliveto, “Time domain identification of hybrid base isolation systems using free vibration tests," Earthquake Engineering and Structural Dynamics, vol. 39, no. 9, pp. 1015-1038, 2010.

[22] Y. Robert-Nicoud, B. Raphael, and I. F. C. Smith, "System identification through model composition and stochastic search," Journal of Computing in Civil Engineering, vol. 19, no. 3, pp. 239247, 2005.

[23] T. Furukawa, M. Ito, K. Izawa, and M. N. Noori, "System identification of base-isolated building using seismic response data," Journal of Engineering Mechanics, vol. 131, no. 3, pp. 268275, 2005.

[24] H. Luş, R. Betti, and R. W. Longman, "Identification of linear structural systems using earthquake-induced vibration data,"
Earthquake Engineering and Structural Dynamics, vol. 28, no. 11, pp. 1449-1467, 1999.

[25] J.-N. Juang and R. S. Pappa, "A comparative overview of modal testing and system identification for control of structures," Shock and Vibration Digest, vol. 20, no. 6, pp. 4-15, 1988.

[26] F. Gandhi, K. W. Wang, and L. Xia, "Magnetorheological fluid damper feedback linearization control for helicopter rotor application," Smart Materials and Structures, vol. 10, pp. 96-103, 2001.

[27] J. D. Carlson, W. Matthis, J. R. Toscano, and A. R. McGowan, "Smart prosthetics based on magnetorheological fluids," in Proceedings of the SPIE's 8th Annual International Symposium on Smart Structures and Materials, Newport Beach, Calif, USA, June 2001.

[28] Y. F. Duan, Y. Q. Ni, and J. M. Ko, "State-derivative feedback control of cable vibration using semiactive magnetorheological dampers," Computer-Aided Civil and Infrastructure Engineering, vol. 20, no. 6, pp. 431-449, 2005.

[29] J. N. Juang, Applied System Identification, Prentice-Hall, Englewood Cliffs, NJ, USA, 1994.

[30] J. Juang and M. Q. Phan, Identification and Control of Mechanical Systems, Cambridge University Press, Cambridge, UK, 2001.

[31] M. De Angelis and G. Fraraccio, "Identificazione di strutture eccitate alla base e controllate con dispositivi non lineari," in XII Congresso L'Ingegneria Sismica, Pisa, Italy, 2007 (Italian).

[32] M. De Angelis and M. Imbimbo, "A procedure to identify the modal and physical parameters of a classically damped system under seismic motions," Advances in Acoustics and Vibration, vol. 2012, Article ID 975125, 11 pages, 2012.

[33] V. Sepe, D. Capecchi, and M. De Angelis, "Modal model identification of structures under unmeasured seismic excitations," Earthquake Engineering and Structural Dynamics, vol. 34, no. 7, pp. 807-824, 2005.

[34] D. Capecchi, M. De Angelis, and V. Sepe, "Modal model identification with unknown nonstationary base motion," Meccanica, vol. 39, no. 1, pp. 31-45, 2004.

[35] M. Basili, M. De Angelis, and E. Renzi, "Caratterizzazione di un dispositivo di tipo Magnetoreologico mediante prove sperimentali," in Proceedings of the XVII Congresso AIMETA, Firenze, Italy, 2005 (Italian).

[36] B. F. Spencer Jr., S. J. Dyke, M. K. Sain, and J. D. Carlson, "Phenomenological model for magnetorheological dampers," Journal of Engineering Mechanics, vol. 123, no. 3, pp. 230-238, 1997.

[37] M. I. Friswell and J. E. Mottershead, Finite Element Model Updating in Structural Dynamics, vol. 38 of Solid Mechanics and its Applications, Kluwer Academic, Dordrecht, Netherlands, 1995.

[38] P. G. Bakir, E. Reynders, and G. De Roeck, "Sensitivity-based finite element model updating using constrained optimization with a trust region algorithm," Journal of Sound and Vibration, vol. 305, no. 1-2, pp. 211-225, 2007. 


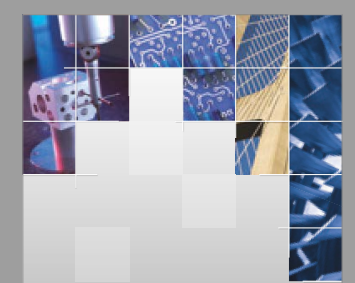

\section{Enfincering}
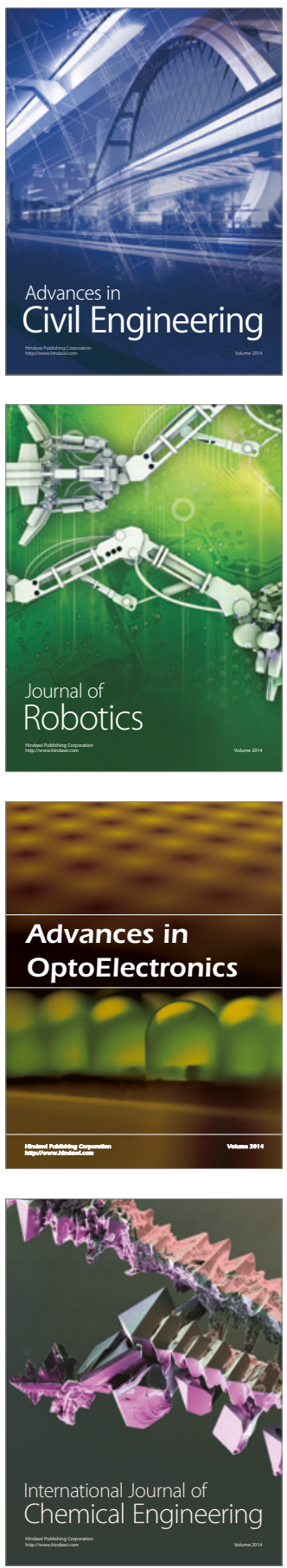

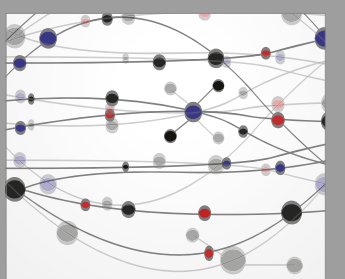

The Scientific World Journal

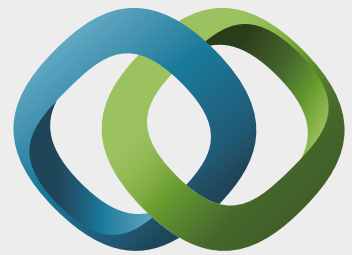

\section{Hindawi}

Submit your manuscripts at

https://www.hindawi.com
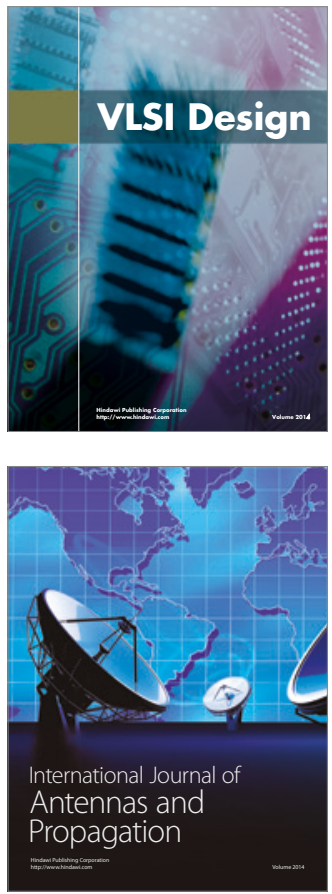

\section{Rotating}

Machinery
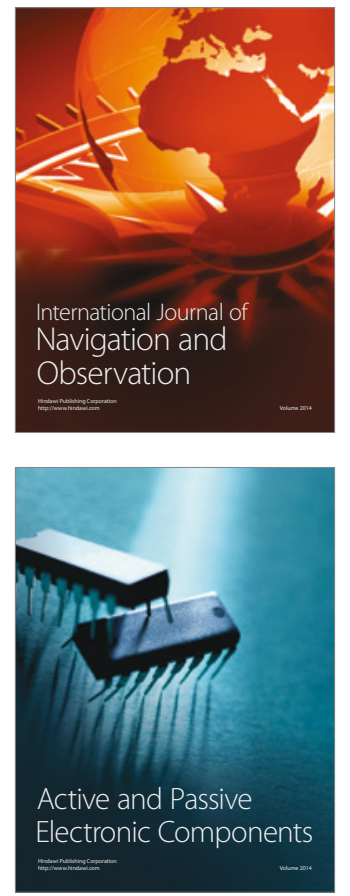
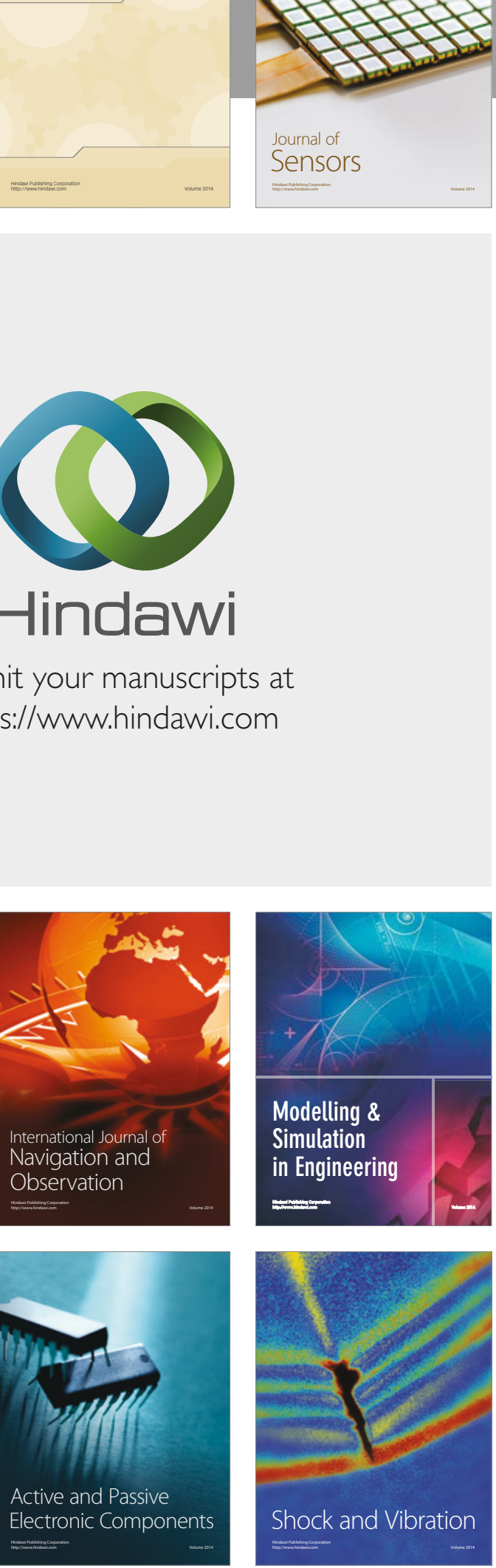
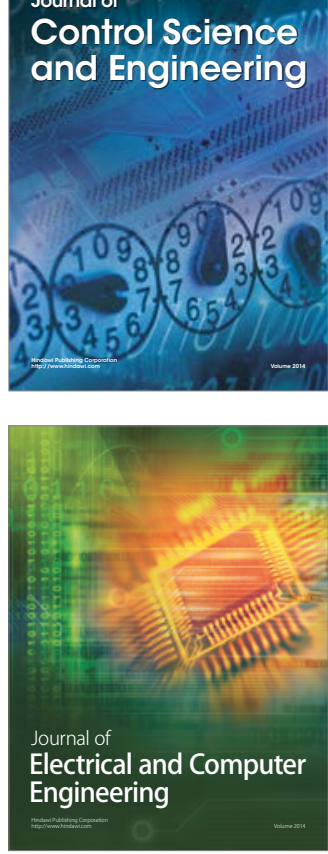

Distributed

Journal of

Control Science

and Engineering
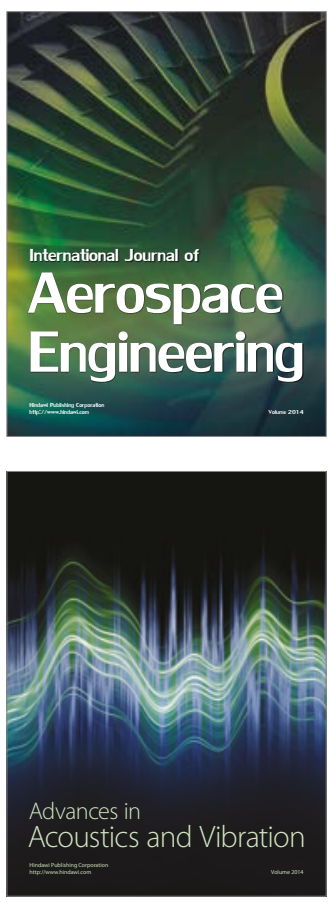

Sensor Networks 